\title{
BENCHMARK EXERCISE FOR FLUID FLOW SIMULATIONS IN A LIQUID METAL FAST REACTOR FUEL ASSEMBLY
}

E. Merzari ${ }^{1}$, P. Fischer ${ }^{1}$, H. Yuan ${ }^{5}$, K. van Tichelen ${ }^{2}$, S. Keijers ${ }^{2}$, J. De Ridder ${ }^{3}$, J. Degroote $^{3}$, J. Vierendeels ${ }^{3}$, H. Doolaard ${ }^{4}$, V.R. Gopala ${ }^{4}$, F. Roelofs ${ }^{4}$

${ }^{1}$ Mathematics and Computer Science Division,

Argonne National Laboratory,

E-mail: emerzari@anl.gov

Phone: +16302526637

9700 S Cass Avenue, Lemont, IL, 60439, USA

${ }^{2} \mathrm{SCK} \cdot \mathrm{CEN}$, Brussels, Belgium

${ }^{3}$ University of Ghent, Ghent, Belgium

${ }^{4} \mathrm{NRG}$, Netherlands

${ }^{5}$ Nuclear Engineering Division, Argonne National Laboratory, Lemont, Illinois, USA

\section{ABSTRACT}

As part of a Department of Energy International Nuclear Energy Research Initiative (I-NERI), Argonne National Laboratory (Argonne) is collaborating with the Dutch Nuclear Research and consultancy Group (NRG), the Belgian Nuclear Research Centre (SCK• $\cdot \mathrm{CEN})$, and Ghent University (UGent) in Belgium to perform and compare a series of fuel-pin-bundle calculations representative of a fast reactor core. A wirewrapped fuel bundle is a complex configuration for which few data are available for verification and validation of new simulation tools.

UGent and NRG performed their simulations with commercially available computational fluid dynamics (CFD) codes. The high-fidelity Argonne large-eddy 
simulations were performed with Nek5000, used for CFD in the Simulation-based Highefficiency Advanced Reactor Prototyping (SHARP) suite. SHARP is a versatile tool that is being developed to model the core of a wide variety of reactor types under various scenarios. It is intended to both serve as a surrogate for physical experiments but also provide insight for experimental results.

Comparison of the results obtained by the different participants with the reference Nek5000 results shows good agreement, especially for the cross-flow data. The comparisons also help to highlight issues with current modeling approaches.

The results of the study are very valuable in the design and licensing process for MYRRHA, a flexible fast- research reactor under design at SCK $\cdot \mathrm{CEN}$. It has wirewrapped fuel bundles cooled by Lead Bismuth Eutectic. 


\section{INTRODUCTION}

Nuclear power plays an important role in power generation and produces about $16 \%$ of the total electricity worldwide. The rapidly growing energy demand suggests a persistent important role for nuclear power in the future energy supply, as outlined in the projections of the World Energy Outlook 2013 (IEA, 2013). On a global scale, the accident at the Fukushima Daiichi nuclear power plant in Japan in March 2011 did have a minor effect on the future demand for nuclear power. Beyond fossil fuels, IEA (2013) calculates that nuclear power maintains at a $12 \%$ share of electricity generation globally by 2035, with expansion mainly occurring in Asia. In Europe, in the Vision Report (SNETP, 2007) of the Sustainable Nuclear Energy Technology Platform (SNETP), a large role is attributed to the deployment of fast reactors. The preferred option is the sodium cooled fast reactor with the lead cooled fast reactor as one of the two back-ups. This clearly shows the importance of liquid metals in the development of future nuclear energy technologies. For an elaborate overview of the status of fast reactor development the reader is referred to IAEA, 2012.

Thermal-hydraulics is recognized as one of the key scientific subjects in the design and safety analysis of liquid metal cooled reactors. To solve thermal-hydraulic issues, nuclear engineers apply experiments, analytical and empirical correlations, system thermal hydraulics (STH) codes, or sub-channel codes. Additionally, Computational Fluid Dynamics (CFD) techniques are becoming more and more integrated in the daily practice 
of the thermal-hydraulics researchers and designers. Roelofs et al. (2013b) summarize the status and the future challenges for CFD application to liquid metal cooled fast reactors. They show that for many liquid metal fast reactor thermal-hydraulic issues, the validation of CFD techniques is and will always remain a key issue. In general, they show the simultaneous need for developments with respect to experiments including measurement techniques and numerical simulations.

Under the Department of Energy's International Nuclear Energy Research Initiative (INERI), Argonne National Laboratory (Argonne) collaborates with three Euratom members: the Dutch Nuclear Research and consultancy Group (NRG), the Belgian Nuclear Research Centre (SCK•CEN), and Ghent University (UGent) in Belgium on simulations of nuclear reactor core flows. The aim is to share data produced by the partners involved to systematically cross-verify fluid-dynamic simulations in liquid metal cooled nuclear reactor fuel assemblies. This collaboration focuses on code-to-code CFD comparisons in the absence of CFD-grade experimental data for wire-wrapped fuel assemblies.

In fact, most liquid metal cooled fast reactor designs employ wire wraps as spacers between the individual pins in a rod bundle. Although many experiments have been performed in the past, Roelofs et al. (2013a) clearly demonstrate that CFD grade validation data is not available. New thermal-hydraulic experiments are under preparation now in Germany, Italy and the United States to fill this gap. In order to gain confidence in their employed Reynolds Averaged Navier Stokes (RANS) approaches, the partners in 
this collaboration compare their results from RANS approaches with data from high fidelity Large Eddy Simulations (LES) performed at ANL in a blind benchmark. Explanations of the various CFD modelling approaches can be found in Roelofs et al. (2013a). These explanations basically show that Direct Numerical Simulations and LES can provide high fidelity reference data for comparison with more pragmatic RANS or hybrid approaches. The current paper describes the simulation efforts shared by the collaborating partners. Discrepancies or concerns with current prediction technologies will be identified. Furthermore, an experimental plan for validation will be then developed taking into account the concerns which emerged from this collaboration.

The study is part of the code validation and verification approach developed in the licensing process of the Multi-purpose hYbrid Research Reactor for High-tech Applications (MYRRHA), currently under design at SCK •CEN (Ait Abderrahim, 2012). MYRRHA is a flexible fast spectrum research reactor with wire-wrapped fuel bundles cooled by Lead Bismuth Eutectic. MYRRHA is identified as the European Technology Pilot Plant for the Lead Cooled Fast Reactor (LFR) which is one of the Generation IV reactor concepts (SNE-TP, 2010).

Argonne performed several wire-wrapped analyses as part of the NEAMS initiative (Pointer et al., 2008, Pointer et al. 2009, Smith et al. 2008). In particular, a 7-pin wirewrapped simulation performed with the LES code Nek5000 has been performed. These calculations are used as the basis for a blind benchmark calculation between the collaborating partners. We emphasize that, while pin counts in actual liquid metal 
assemblies are much higher, code comparisons in small assemblies are useful to build confidence in numerical and modeling practices at an early stage. In fact, code-to-code comparisons in large assemblies are computationally expensive and present significant logistic challenges due to the large amount of data and the presence of multiple physical phenomena. Code- to-code comparisons in progressively larger assemblies are nevertheless planned (see OUTLOOK session).

The present article summarizes the Nek5000 code (section on COMPUTATIONAL TOOLS), describes briefly the benchmark exercise (section on BENCHMARK EXERCISE) and presents the comparisons of the benchmark datasets (section on COMPARISONS RESULTS) to the Argonne high fidelity reference LES data. The results confirmed previous findings (i.e, the good performance of the k- $\omega$ SST model in this type of modeling) and highlight the importance of consistent geometry in code-tocode comparisons.

\section{COMPUTATIONAL TOOLS}

\subsection{SHARP suite}

The SHARP (Siegel et al., 2007, Mahadevan et al., 2014) project at Argonne is a multidivisional collaborative effort to develop a modern set of design and analysis tools for advanced nuclear reactors. SHARP is an integral part of the NEAMS RPL. With the 
SHARP suite, users construct complex virtual reactor models that accurately integrate the governing physics to evaluate the performance of the reactor in a wide variety of operational or accident scenarios. Alternatively, SHARP users may construct highly detailed component models using high-fidelity methods, which rely on few or no engineering models or approximations. The thermal-hydraulic high-fidelity component of SHARP is Nek5000 (Fischer et al. 2008, Fischer et al. 2007), a high-order spectral element code ideally suited for LES or direct numerical simulation (DNS) calculations. In LES, turbulence is only minimally modeled, and the model relies upon large-scale computing to simulate even the smallest scales of turbulence. In DNS, no modeling takes place at all.

The focus of SHARP has been in reproducing accurately the multi-physics behavior of the core of nuclear reactors, since it is within nuclear reactor cores that the suite has the highest potential of being applied to increase performance. In fact, an accurate prediction of local phenomena could give an accurate assessment of key design parameters, such as the peak temperature. A more reliable methodology to estimate parameters can lead to the reduction of arbitrary margins and the testing of new designs, and an overall increase in efficiency. In order for any methodology to be applied successfully, it needs to be thoroughly verified and validated.

\subsection{NEK5000}

The LES simulations at Argonne use the Argonne-based open source fluid/thermal 
simulation code, Nek5000, which has been designed specifically for transitional and turbulent flows in complex domains. Nek5000 is based on the spectral element method (SEM) (Deville, Fischer and Mund, 2002), which is a high-order weighted residual technique that combines the geometric flexibility of finite elements with the rapid convergence and tensor-product efficiencies of global spectral methods. Globally, the SEM is based on a decomposition of the domain into ne smaller subdomains (elements), which are assumed to be curvilinear hexahedra (bricks) that conform to the domain boundaries. Locally, functions within each element are expanded as n-th-order polynomials cast in tensor-product form, which allows differential operators on $(n+1)^{3}$ gridpoints per element to be evaluated with only $\mathrm{O}\left(\mathrm{n}^{4}\right)$ work and $\mathrm{O}\left(\mathrm{n}^{3}\right)$ storage.

The principal advantage of the spectral element method is that convergence is exponential in $\mathrm{n}$, which implies that significantly fewer gridpoints per wavelength are required to accurately propagate a signal (or turbulent structure) over the extended times associated with high Reynolds number flow simulations. The advantage of this approach has been demonstrated in a recent study at NREL (Sprague, 2010), which showed that, for a given accuracy, turbulent channel flow simulations performed with 7th-order spectral elements require half as many gridpoints in each direction as comparable finitevolume-based simulations. Moreover Nek5000 has been validated on several type of flows (Merzari et al., 2013) and in particular rod bundle flows (Walker et al, 2014).

The NREL study further showed that Nek5000 and the popular finite-volume code, OpenFOAM, have essentially the same cost per gridpoint over a wide range of processor 
counts implying that Nek5000 is an order of magnitude more efficient for this class of problems and requires one-tenth the computational resources for the same simulation result.

Temporal discretization is based on a high-order splitting that is 3rd-order accurate in time and reduces the coupled velocity-pressure Stokes problem to four independent elliptic solves per timestep: one for each velocity component and one for the pressure. The velocity problems are diagonally dominant and thus easily solved by using Jacobipreconditioned conjugate gradient iteration. The pressure substep requires a Poisson solve at each step, which is effected through multigrid-preconditioned GMRES iteration coupled with temporal projection to find an optimal initial guess. Particularly important components of Nek5000 are its scalable coarse-grid solvers that are central to parallel multigrid. The code features a fast direct solver that is optimal up to processor counts of $\mathrm{p} \approx 10^{4}$, and fast algebraic multigrid for $\mathrm{p}=10^{5}$ and beyond. Counts of 15 GMRES iterations per timestep for billion-gridpoint problems are typical with the current pressure solver. Nek5000 scales extremely well on the BG/P and BG/Q architectures.

\section{BENCHMARCK EXERCISE}

The participants are collaborating on verification of numerical simulations pertaining to the flow in fuel pin bundles. These bundles typically incorporate spacers, such as wires or grids. Wire-wrapped pin bundles are notably used in liquid metal fast reactors. The 
presence of spacers complicates the flow considerably and the lack of detailed experiments makes the validation of CFD simulations problematic.

As part of the NEAMS Program, Argonne has performed several wire-wrapped analyses with Nek5000. The fuel assembly design of the proposed ABTR (Chang et al. 2006) was selected as the reference pin bundle geometry. The ABTR driver fuel assembly consists of 217 fuel pins arranged in a hexagonal bundle with wire-wrap spacers. Each fuel pin has an outer diameter (D) of $0.8 \mathrm{~cm}$ and a total height of $260 \mathrm{~cm}$. The center-to-center pin pitch is $0.908 \mathrm{~cm}$. Each pin is spirally wrapped with a single 0.103 -cm-diameter wire spacer with an axial wire wrap pitch (H/D) of 26.6. The pitch to diameter ratio (P/D) is equal to 1.13494. Argonne used these dimensions to develop three 7-pin configurations and one 217-pin configuration for modeling, with the primary focus on the three 7-pin bundles.

The 7-pin configuration is shown in Fig. 1. The center-to-center pin pitch of $0.908 \mathrm{~cm}$ results in a spacing of $0.108 \mathrm{~cm}$ between the pins. The same spacing is maintained between the pins and the can wall, which has an inner flat-to-flat diameter (F) of $2.59 \mathrm{~cm}$ (3.2375 D). Each pin, when viewed from above, is wrapped with a counter-clockwise spiral of wire. In the actual calculations, all dimensions are normalized by the pin diameter.

In the computational model, the wire is represented as embedded within the pin and smoothed (Fig. 2). The shape of the filet was selected to simplify mesh generation while 
at the same time provide a representative dataset. Several studies have been conducted on the effect of pin-wire contact modeling (Merzari et al., 2012). While the effect of pinwire contact has an impact on the peak surface temperature in conjugate heat transfer calculations, it has no significant impact on the global hydraulic effects. Moreover, there are calculations planned with a significant reduction in filet radius.

A nominal gap of $0.005 \mathrm{~cm}$ is kept between each pin-wire ensemble and the other pins.

Two cases will be considered here based on the Reynolds number $\left(R e_{D}=D u_{b u l k} / v\right)$ as shown in Table 1 and 2.

Note that in all LES, only a single wire span is simulated with periodic boundary conditions in the stream-wise direction. All simulations are isothermal. Figure 2 shows the computational mesh for the 7-pin LES. The heavy lines indicate the spectral element boundaries, while the lighter lines show the underlying tensor-product Gauss-LobattoLegendre grid within each element. Figure 2 (right) shows the four principal subchannel interfaces separating: (1) interior channels (A-A), (2) interior and edge channels $(\mathrm{B}-\mathrm{B})$, (3) corner and edge channels $(\mathrm{C}-\mathrm{C})$, and (4) edge and corner channels (D-D). The symmetry-breaking induced by the spiraling wire wrap implies that $\mathrm{C}-\mathrm{C}$ and $\mathrm{D}-\mathrm{D}$ are distinct. In general, the number of distinct interfaces will scale as a multiple of the number of pins because the position of the subchannel with respect to the subassembly wall is significant. 
The mesh consists of 108 levels, each comprising 1,224 elements (ne), for a total of ne $=132,192$. To simplify the meshing, a fillet is added where each wire contacts its companion fuel pin. Several element orders, ranging from 4 to 11, have been used. As an example, for a $7^{\text {th }}$ order polynomial $(n=7)$, the total number of collocation points $(n p)$ is 44 million ( 756 points axially $\times 58,542$ per plane). In all cases, there are 6 elements, or roughly 42 gridpoints, spanning each subchannel. The $y+$ of the first point near wall is below 1 everywhere, and more than 5 collocation points are located within the viscous sub-layer.

Figures 3 through 6 show details of the spectral element mesh for simulation 1. Figures 3 and 4 illustrate the wire orientation at two different heights in the bundle, and Figs. 5 and 6 show details of the mesh where the wire is adjacent to a pin or the edge of the bundle can. Figure 7 shows instantaneous velocity distributions throughout the domain, obtained by an Argonne LES. Values are normalized by the bulk velocity. After running the simulation for a considerable amount of time, data has been collected for all three rms and velocity components.

The benchmark problem was based on the simulations described, and three sets of comparisons were conducted on each simulation.

1. Comparison C1 - Velocity $(\mathrm{u}, \mathrm{v}, \mathrm{w})$, rms profiles ( $\left.\mathrm{u}^{\prime}, \mathrm{v}^{\prime}, \mathrm{w}^{\prime}\right)$, and Reynolds stresses (u'v', v'w', u'w') on lines A-A, B-B, C-C, and D-D 
in Fig. 2 on five stream-wise normal planes spaced uniformly in z [for plane $\mathrm{i}$, the axial height is $\mathrm{z}=\mathrm{i}(\mathrm{H} / 5)]$.

2. Comparison C2 - Velocity (u,v,w), rms profiles ( $\left.\mathrm{u}^{\prime}, \mathrm{v}^{\prime}, \mathrm{w}^{\prime}\right)$, and Reynolds stresses (u'v', v'w', u'w') on Diag1, Diag2, and Diag3 in Fig. 8 on five stream-wise normal planes spaced uniformly in $\mathrm{z}$ [for plane $i$, the axial height is $\mathrm{z}=\mathrm{i}(\mathrm{H} / 5)]$.

3. Comparison C3 - Integral of transversal velocity (cross flow) on lines A-A, B-B, C-C, and D-D in Fig. 2 across the whole stream-wise direction. Data was compared across 200 spaced uniformly in z (only one data point at the periodic boundaries is required).

Comparison C1 included 3,984 points, while comparison C2 included 1,996 points. Comparison C3 required 200 line integrals for each plane. Argonne computed the benchmark cross-flows by interpolating 200 points (using spectrally accurate routines) for each line and then applying the trapezoid rule to estimate the integral. The data is available upon request. 


\section{COMPARISON RESULTS}

The data produced by the Nek5000 simulation was compared to five other calculations: three from NRG and two from UGent representing different computational and turbulence models:

1. NRG-1: computed using a $k-\varepsilon$ cubic model;

2. NRG-2: computed using the k- $\omega$ SST model;

3. NRG-3: computed using a k-ع realizable model;

4. UGent-1: computed using the k- $\omega$ SST model;

5. UGent-2: computed using the k- $\omega$ SST model, with a more accurate surface representation;

The NRG calculations were all performed with STAR-CCM+ (Various authors, 2013a) and two-layer All-y+ wall modeling. The submissions from UGent were conducted with ANSYS ${ }^{\circledR}$ Fluent ${ }^{\circledR}$ (Various authors, 2013b). The calculations have been performed without knowledge of the Argonne results. The comparisons made below are limited to a simple "error check." Errors for each of the three submissions were computed based on the following rms formula:

$$
E=\sqrt{\frac{1}{N} \sum_{i=1}^{N}\left(f_{i}-f_{i}^{A N L}\right)^{2}}
$$

Where $\mathrm{N}$ is the number of points for each comparison and $f_{i}$ represents the value of the function that is being compared for the given submission. 
The submission closest to the Argonne results is NRG-2 (computed using the k$\omega$ SST model). This is apparent from Table 3, which reports the error as a percentage of the bulk velocity. UGent-2 is also very close to Argonne's results, with occasionally better results than NRG-2. Overall UGent-2 showed some discrepancy at the higher Reynolds number. All other submissions performed better at the higher Reynolds number, but the k- $\omega$ SST model seems to perform better overall. The reason for this behavior, observed in previous Argonne studies (Pointer et al., 2008, Pointer et al., 2009, Smith et al., 2008), is unclear.

In the following a brief discussion of the detailed velocity profiles can be found (Fig. 9, Fig. 10, Fig. 11). The velocity is shown as a function of the curvilinear coordinate $s$ normalized by the total wall-to-wall distance $S$. All velocity values are normalized by the bulk velocity $\mathrm{U}_{\text {bulk. }}$ More velocity profiles can be found in Merzari and Fischer, 2013. It is possible to notice how in the narrow gap region:

- No turbulence model is able to handle the flow in direct wake of the wire (Fig. 9a), when compared to LES.

- Most turbulence models reproduce accurately the flow when the wire is not present or relatively far (Fig. 9b).

- $\mathrm{k}-\omega \mathrm{SST}$ reproduces correctly the behavior in the immediate proximity of the wire while all other k- $\varepsilon$ models underestimate it (Fig. 9c).

In fact, the discrepancy between submission NRG-2 and the Argonne data is limited to the region immediately downstream of the wire, in its wake (simulations 1 and 2, stream- 
wise-normal plane 2 at $\mathrm{z}=2 \mathrm{H} / 5$, sections $\mathrm{A}-\mathrm{A}$ and $\mathrm{B}-\mathrm{B}$ ), or upstream of the wire when the Reynolds number is low (simulation 1, stream-wise-normal plane 1 at $\mathrm{z}=\mathrm{H} / 5$, sections $\mathrm{C}$ C and D-D),. The region in the wake of the wire, where shedding is likely to be present, is problematic to predict with traditional turbulence modeling. This is a region of considerable interest, since it is also the region where the peak cladding temperature is located (Merzari et al., 2012).

Moreover, it should be noted that the non-dimensional profiles (Fig. 10) in the narrow gap region can be approximated reasonably well by traditional law of the wall profiles when the wire is not in the vicinity (Fig. 10a). However when the wire approaches the narrow gap, the profiles differ significantly from traditional law of the wall profiles (Fig. 10b). All RANS models will be expected to have issues predicting correctly the flow in these conditions.

The diagonals show similar patterns (Fig. 11). The streamwise velocity in the first portion of diagonal 1 at $\mathrm{z} / \mathrm{D}=5.32$ is more problematic for RANS models than the second part. The first portion is in fact influenced by the presence of the wire in the vicinity of the plane. Figure 12 displays the cross velocity in diagonal 1. It is possible to notice how the distribution is less sensitive to code or turbulence model.

The University of Gent submission UGent-1 is less accurate than the NRG counterpart (NRG-2) despite the use of the same turbulence model. This can be related to meshing issues encountered by the UGent team, which after being solved in submission 
UGent-2 led to better results, very close to NRG-2. The better results are related to the better representation of the surface (Fig. 13). It should also be noted that the UGent-2 results, which were submitted after the conclusion of the blind benchmark phase led to a result significantly closer to the ANL results even in the proximity of the wire (Fig. 9).

The errors for the cross-flow comparisons for all submissions and for section A-A to C-C are listed in Table 4.

As with the previous comparisons, the k- $\omega$ SST model showed the best performance, but all turbulence models yielded reasonable predictions, confirming previous research (Pointer et al, 2008, Pointer et al, 2009, Smith et al, 2008) showing that RANS-based modeling can be used to predict cross-flows with reasonable accuracy. For submissions UGhent-2, and NRG-1, the error is roughly $1 \%$ for all channels, with discrepancies with the LES results clustered around the axial position where the wire crosses the sub-channel plane. In fact, despite the differences between the submissions, the cross flows predictions are very similar (Fig. 14, 15), the predictions are not significantly affected by the Reynolds number. In Both Fig. 14 and Fig. 15 UGent-1 results are used. UGent-2 results have similar behavior to NRG-2.

\section{CONCLUSIONS}


The exercise described in this article has proven to be a useful venue for discussing and comparing results of CFD codes across the entire spectrum of fidelity used by the SHARP toolkit and commercial codes like STAR-CCM+.

Comparison of the results obtained by the three institutions has shown good agreement at least for the cross-flow data (with an error below 5\% for every calculation, Ugent-2, and NRG-2 have maximum errors below 1.5\%). Direct comparisons for the local velocity yielded mixed results, with the only k- $\omega$ SST model (both the NRG and UGent submissions) slightly outperforming the other turbulence models and being the closest to Argonne's LES data. This confirmed previous results, due to a better performance of k- $\omega$ SST in predicting the region in the proximity of the wire (while not in its wake). This should not be interpreted as a strong endorsement of the k- $\omega$ SST model but rather an invitation to further investigate advanced turbulence modeling in this geometry., as more sophisticated modeling is likely to lead to better results.

Advanced turbulence modeling work will benefit from the data produced by this collaboration. High resolution experimental investigations are however necessary and are recommended for further modeling development. Experiments that investigate flow structures with a high level of resolution (PIV, LDV) in non-trivial wire-wrapped rod bundles are also needed to validate the present results.

Moreover, an initial submission with k- $\omega$ SST from the UGent group and its subsequent modification demonstrated the sensitivity of CFD modeling simulations in this geometry 
on the surface description. This emphasizes the importance of conducting the simulations with accurate and consistent geometry and surface description, at a high level of detail.

The verification and validation of computer codes forms an integral part of the Quality Assurance associated with the development of the Preliminary Safety Assessment for MYRRHA. The code-to-code comparison, presented in this paper, allows testing turbulence models and meshing strategies in a configuration that is representative of the MYRRHA fuel bundle. It allows to assess the limitations and uncertainties associated with RANS approach with regards to an LES approach. Moreover, the lessons learned from this validation exercise are implemented by CFD analysts in their models supporting the design and safety analysis of MYRRHA.

\section{OUTLOOK}

MYRRHA (Multi-purpose hYbrid Research Reactor for High-tech Applications), currently under design at $\mathrm{SCK} \cdot \mathrm{CEN}$ (Ait Abderrahim, 2012), is a flexible fast spectrum research reactor cooled by Lead Bismuth Eutectic. Conceived as an accelerator driven system (ADS) prototype, it is able to operate in sub-critical mode. Operating in critical mode, MYRRHA is identified as the European Technology Pilot Plant for the Lead Cooled Fast Reactor (LFR) which is one of the Generation IV reactor concepts (SNE-TP, 2010).

In addition to the work presented here, the participants in this benchmark also performed a 19-pin wire-wrapped conjugate heat transfer benchmark. The geometry is related to the 
assembly design of MYRRHA. Results for this benchmark will be summarized in a coming paper. Moreover, work on this topic will continue in both the NEAMS and SESAME projects, as part of the verification activities of the computational fluid dynamic simulation of liquid metal assemblies.

\section{NOMENCLATURE}

$\begin{array}{ll}\mathrm{n} & \text { Polynomial order, in the spectral element method } \\ \mathrm{ne} & \text { Number of elements, in the spectral element method } \\ \mathrm{np} & \text { Total number of collocation points, in the spectral element method } \\ \mathrm{p} & \text { Number of processors } \\ \mathrm{P} & \text { Center-to-center pin pitch } \\ \mathrm{D} & \text { Pin diameter } \\ \mathrm{g} & \text { Gap size (g=P-D) } \\ \mathrm{P} / \mathrm{D} & \text { Pitch-to-Diameter ratio } \\ \mathrm{F} & \text { Flat-to-flat } \\ \mathrm{D}_{\mathrm{h}} & \text { Hydraulic Diameter } \\ \mathrm{H} & \text { Axial wire pitch } \\ \mathrm{H} / \mathrm{D} & \text { Axial wire-pitch to diameter ratio } \\ \mathrm{u}_{\text {bulk }} & \text { Bulk velocity } \\ \mathrm{Re} & \text { Reynolds number, based on hydraulic diameter } \\ \mathrm{Re} & \text { Reynolds number, based on pin diameter } \\ v & \text { Kinematic viscosity }\end{array}$




$\begin{array}{ll}\mathrm{x}, \mathrm{y}, \mathrm{z} & \text { Cartesian Coordinates } \\ \mathrm{u}, \mathrm{v}, \mathrm{w} & \text { Velocity components in the Cartesian coordinates } \\ \mathrm{u}^{\prime}, \mathrm{v}^{\prime}, \mathrm{w}^{\prime} & \begin{array}{l}\text { Root mean square of the velocity fluctuations in the Cartesian } \\ \text { coordinates }\end{array} \\ \mathrm{k} & \text { Turbulent Kinetic Energy } \\ \varepsilon & \text { Dissipation of Turbulent Kinetic Energy } \\ \omega & \text { Rate of Dissipation of the turbulent Kinetic Energy } \\ \mathrm{E} & \text { Average Error }\end{array}$

\section{ACKNOWLEDGEMENT}

The submitted manuscript has been created by UChicago Argonne, LLC, Operator of Argonne National Laboratory ("Argonne"). Argonne, a U.S. Department of Energy Office of Science laboratory, is operated under Contract No. DE-AC02-06CH11357. The U.S. Government retains for itself, and others acting on its behalf, a paid-up nonexclusive, irrevocable worldwide license in said article to reproduce, prepare derivative works, distribute copies to the public, and perform publicly and display publicly, by or on behalf of the Government.

The UGent contribution of the work described in this paper was funded by the Research Foundation - Flanders (FWO) with a PhD fellowship and a postdoctoral fellowship.

The Dutch contribution of the work described in this paper was funded by the Dutch Ministry of Economic Affairs. Part of this work was supported by the FP7 EC Collaborative Project THINS no. 249337. 


\section{REFERENCES}

Abderrahim, H. A., Multi-purpose hYbrid Research Reactor for High-tech Applications a multipurpose fast spectrum research reactor. Int. J. Energy Res., 36: 1331-1337, 2012

Chang, Y.I., Finck, P.J., and Grandy, C., Advanced Burner Test Reactor Preconceptual Design Report, ANL-ABR-1 and ANL-AFCI-173, Argonne National Laboratory, September 6, 2006.

Deville, MO., Fischer, PF. and Mund, EH., 2002. "Higher order methods for incompressible fluid flow," Cambridge Univ. Press.

IAEA, 2012. Status of Fast Reactor Research and Technology Development. Technical Report 474, ISBN 978-92-0-130610-4, Vienna, Austria.

IEA, 2013. World Energy Outlook 2013. London, UK.

Fischer, P., Lottes, J., Pointer, W.D., and Siegel, A., 2008, "Petascale Algorithms for Reactor Hydrodynamics," J. Phys. Conf. Series,

Fischer, P., Lottes, J., Siegel, A., and Palmiotti, P., 2007 "Large Eddy Simulation of Wire-Wrapped Fuel Pins I: Hydrodynamics in a Periodic Array," in Proceedings of the Joint International Topical Meeting on Mathematics and Computations and Supercomputing in Nuclear Applications ( $M \& C+S N A)$, American Nuclear Society, April 2007.

Mahadevan, V., Merzari, E., Tautges, T., Jain, R., Obabko, A., Smith, M. and Fischer, P. , 2014, "High resolution coupled physics solvers for analyzing finescale nuclear reactor design problems", Philosophical Transactions A (in press)

Merzari, E., Fischer, P., 2013, "Benchmark exercise for fluid simulations in a liquid metal fast reactor core." Argonne Report ANl/NE-19

Merzari, E., Fischer, P., Pointer, W. D., 2013, "Numerical Simulation and Proper Orthogonal Decomposition of the flow in a Counter Flow T-junction." Journal Fluids Engineering, 135, 091304.

Merzari E., Pointer W.D., Smith J.G., Tentner A., and Fischer, P., 2012, "Numerical Simulation of the Flow in Wire-wrapped Pin Bundles: Effect of Pin-wire Contact Modeling," Nuclear Engineering and Design, 253:374-386.

Pointer, W.D., Thomas, J.W., Fanning, T., Fischer, P. and Siegel, A., 2009, "RANSBased CFD Simulations of Sodium Fast Reactor Wire-Wrapped Pin Bundles," in 
Proceedings International Conference on Mathematics, Computational Methods and Reactor Physics, Saratoga Springs, NY, May 3-7, 2009.

Pointer, W.D., Fischer, P., Siegel, A. and Smith, J.G., 2008, "RANS-based CFD Simulations of Wire-Wrapped Fast Reactor Fuel Assemblies," in Proceedings of ICAPP '08, Anaheim, CA, 2008.

Roelofs F., Gopala V.R., Jayaraju S., Shams A., Komen E.M.J., 2013a. Review of Fuel Assembly and Pool Thermal Hydraulics for Fast Reactors. Nuclear Engineering and Design, vol. 265, p.p. 1205-1222.

Roelofs F., Gopala V.R., Van Tichelen K., Cheng X., Merzari E., Pointer W.D., $2013 b$. Status and Future Challenges of CFD for Liquid Metal Cooled Reactors. FR13, Paris, France.

Siegel, A., Tautges, T., Caceres, A., Kaushik, D., Fischer, P., Palmiotti, G., Smith, M.A., and Ragusa, J., 2007, "Software Design of SHARP," in Proceedings of the Joint International Topical Meeting on Mathematics and Computations and Supercomputing in Nuclear Applications (M\&C+SNA), American Nuclear Society, April 2007.

Smith, J.G., Pointer, W.D., Fischer, P., and Babbin, B. 2008, "Effects of Mesh Density and Flow Conditioning in Simulating 7-Pin Wire Wrapped Fuel Pins," in Proceedings of ICONE 16, Orlando, FL, 2008.

SNE-TP, 2007. The Sustainable Nuclear Energy Technology Platform, A Vision Report. European Commission, Brussels, Belgium.

SNE-TP, 2010 "ESNII - The European Sustainable Nuclear Industrial Initiative, A contribution to the EU Low Carbon Energy Policy: Demonstration Programma for Fast Neutron Reactors - Concept paper", Sustainable Nuclear Energy Technology Platform, www.snetp.eu, 2010.

Sprague, M. 2010, “A comparison of Nek5000 and OpenFOAM for the DNS of turbulent channel flow”, Nek5000 users meeting, 10 December 2010 -

http://www.mcs.anl.gov/ fischer/nek5000/sprague_nek5000_dec2010.pdf

Various Authors, 2013a," STAR-CCM+ v8.02 Users Manual"

Various Authors, 2013b," ANSYS® Fluent® 14.0 Users Manual”

Walker, J., Merzari, E., Obabko, A., Fischer, P., Siegel, A. 2014, “Accurate Prediction of the Wall Shear Stress in Rod Bundles with the Spectral Element Method at High Reynolds Numbers", International journal of Heat and Fluid Flow (in press) 


\section{BIBLIOGRAPHY}

Abderrahim, H. A., Multi-purpose hYbrid Research Reactor for High-tech Applications a multipurpose fast spectrum research reactor. Int. J. Energy Res., 36: 1331-1337, 2012

Chang, Y.I., Finck, P.J., and Grandy, C., Advanced Burner Test Reactor Preconceptual Design Report, ANL-ABR-1 and ANL-AFCI-173, Argonne National Laboratory, September 6, 2006.

Deville, MO., Fischer, PF. and Mund, EH., 2002. "Higher order methods for incompressible fluid flow," Cambridge Univ. Press.

IAEA, 2012. Status of Fast Reactor Research and Technology Development. Technical Report 474, ISBN 978-92-0-130610-4, Vienna, Austria.

IEA, 2013. World Energy Outlook 2013. London, UK.

Fischer, P., Lottes, J., Pointer, W.D., and Siegel, A., 2008, "Petascale Algorithms for Reactor Hydrodynamics," J. Phys. Conf. Series,

Fischer, P., Lottes, J., Siegel, A., and Palmiotti, P., 2007 "Large Eddy Simulation of Wire-Wrapped Fuel Pins I: Hydrodynamics in a Periodic Array," in Proceedings of the Joint International Topical Meeting on Mathematics and Computations and Supercomputing in Nuclear Applications $(M \& C+S N A)$, American Nuclear Society, April 2007.

Mahadevan, V., Merzari, E., Tautges, T., Jain, R., Obabko, A., Smith, M. and Fischer, P. , 2014, "High resolution coupled physics solvers for analyzing finescale nuclear reactor design problems", Philosophical Transactions A (in press)

Merzari, E., Fischer, P., 2013, "Benchmark exercise for fluid simulations in a liquid metal fast reactor core." Argonne Report ANl/NE-19

Merzari, E., Fischer, P., Pointer, W. D., 2013, "Numerical Simulation and Proper Orthogonal Decomposition of the flow in a Counter Flow T-junction." Journal Fluids Engineering, 135, 091304.

Merzari E., Pointer W.D., Smith J.G., Tentner A., and Fischer, P., 2012, "Numerical Simulation of the Flow in Wire-wrapped Pin Bundles: Effect of Pin-wire Contact Modeling," Nuclear Engineering and Design, 253:374-386.

Pointer, W.D., Thomas, J.W., Fanning, T., Fischer, P. and Siegel, A., 2009, "RANSBased CFD Simulations of Sodium Fast Reactor Wire-Wrapped Pin Bundles," in Proceedings International Conference on Mathematics, Computational Methods and Reactor Physics, Saratoga Springs, NY, May 3-7, 2009. 
Pointer, W.D., Fischer, P., Siegel, A. and Smith, J.G., 2008, "RANS-based CFD Simulations of Wire-Wrapped Fast Reactor Fuel Assemblies," in Proceedings of ICAPP '08, Anaheim, CA, 2008.

Roelofs F., Gopala V.R., Jayaraju S., Shams A., Komen E.M.J., 2013a. Review of Fuel Assembly and Pool Thermal Hydraulics for Fast Reactors. Nuclear Engineering and Design, vol. 265, p.p. 1205-1222.

Roelofs F., Gopala V.R., Van Tichelen K., Cheng X., Merzari E., Pointer W.D., 2013b. Status and Future Challenges of CFD for Liquid Metal Cooled Reactors. FR13, Paris, France.

Siegel, A., Tautges, T., Caceres, A., Kaushik, D., Fischer, P., Palmiotti, G., Smith, M.A., and Ragusa, J., 2007, "Software Design of SHARP," in Proceedings of the Joint International Topical Meeting on Mathematics and Computations and Supercomputing in Nuclear Applications (M\&C+SNA), American Nuclear Society, April 2007.

Smith, J.G., Pointer, W.D., Fischer, P., and Babbin, B. 2008, "Effects of Mesh Density and Flow Conditioning in Simulating 7-Pin Wire Wrapped Fuel Pins," in Proceedings of ICONE 16, Orlando, FL, 2008.

SNE-TP, 2007. The Sustainable Nuclear Energy Technology Platform, A Vision Report. European Commission, Brussels, Belgium.

SNE-TP, 2010 "ESNII - The European Sustainable Nuclear Industrial Initiative, A contribution to the EU Low Carbon Energy Policy: Demonstration Programma for Fast Neutron Reactors - Concept paper", Sustainable Nuclear Energy Technology Platform, www.snetp.eu, 2010.

Sprague, M. 2010, "A comparison of Nek5000 and OpenFOAM for the DNS of turbulent channel flow”, Nek5000 users meeting, 10 December 2010 -

http://www.mcs.anl.gov/ fischer/nek5000/sprague_nek5000_dec2010.pdf

Various Authors, 2013a," STAR-CCM+ v8.02 Users Manual”

Various Authors, 2013b," ANSYS® Fluent ${ }^{\circledR}$ 14.0 Users Manual”

Walker, J., Merzari, E., Obabko, A., Fischer, P., Siegel, A. 2014, “Accurate Prediction of the Wall Shear Stress in Rod Bundles with the Spectral Element Method at High Reynolds Numbers", International journal of Heat and Fluid Flow (in press) 


\section{FIGURES}

a)
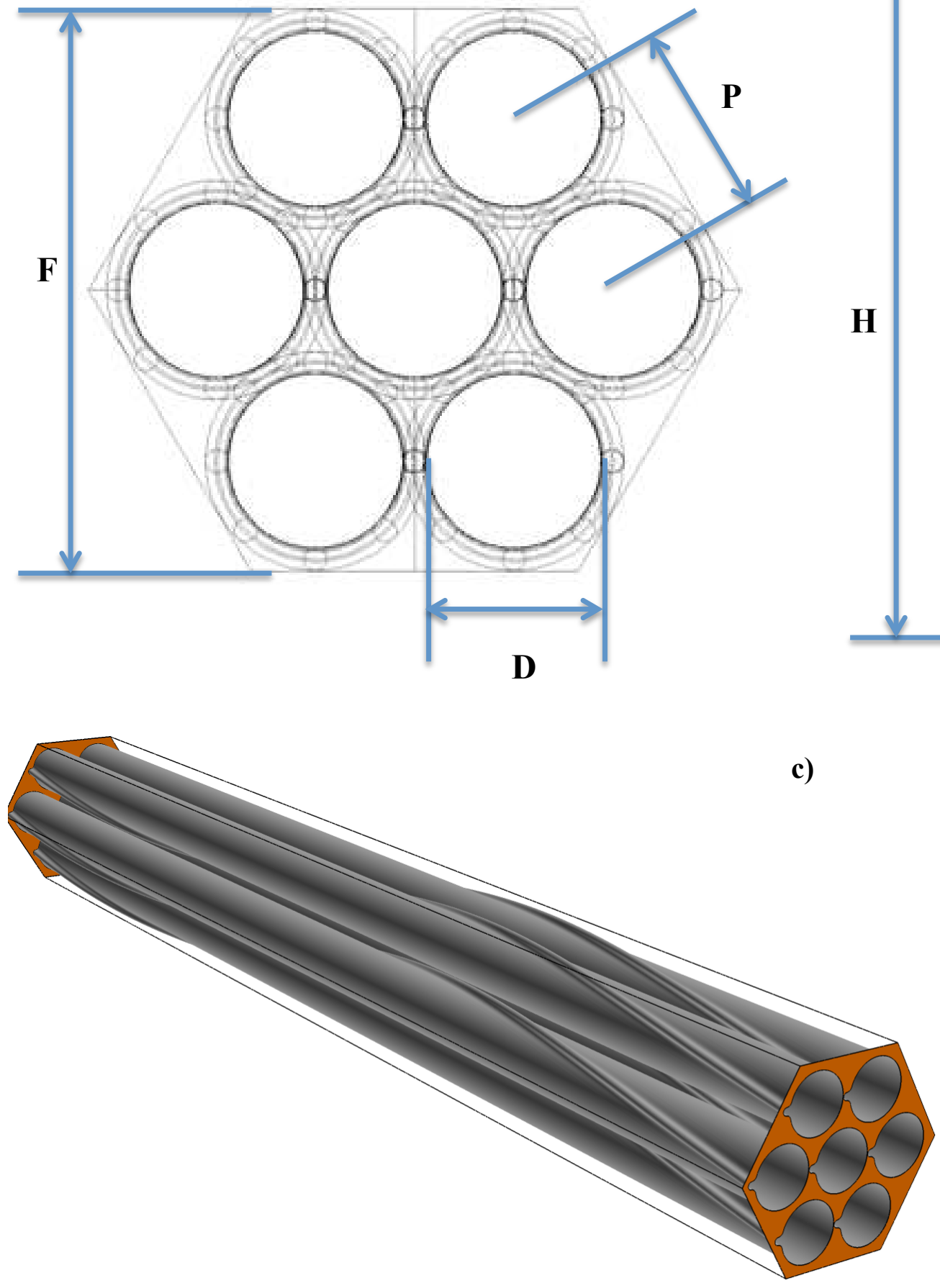

FIGURE 1 Wire-wrap Configuration in 7-pin Bundle.

a) top-view, b) side-view, c) 3D view. b)

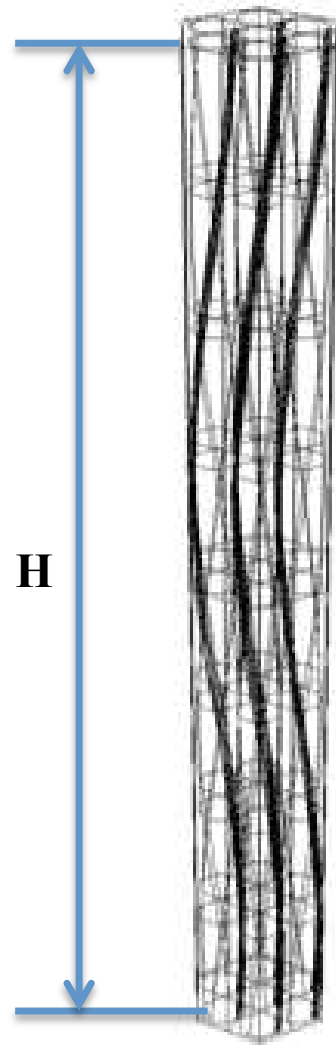

a) top-view, b) side-view, c) 3D view. 

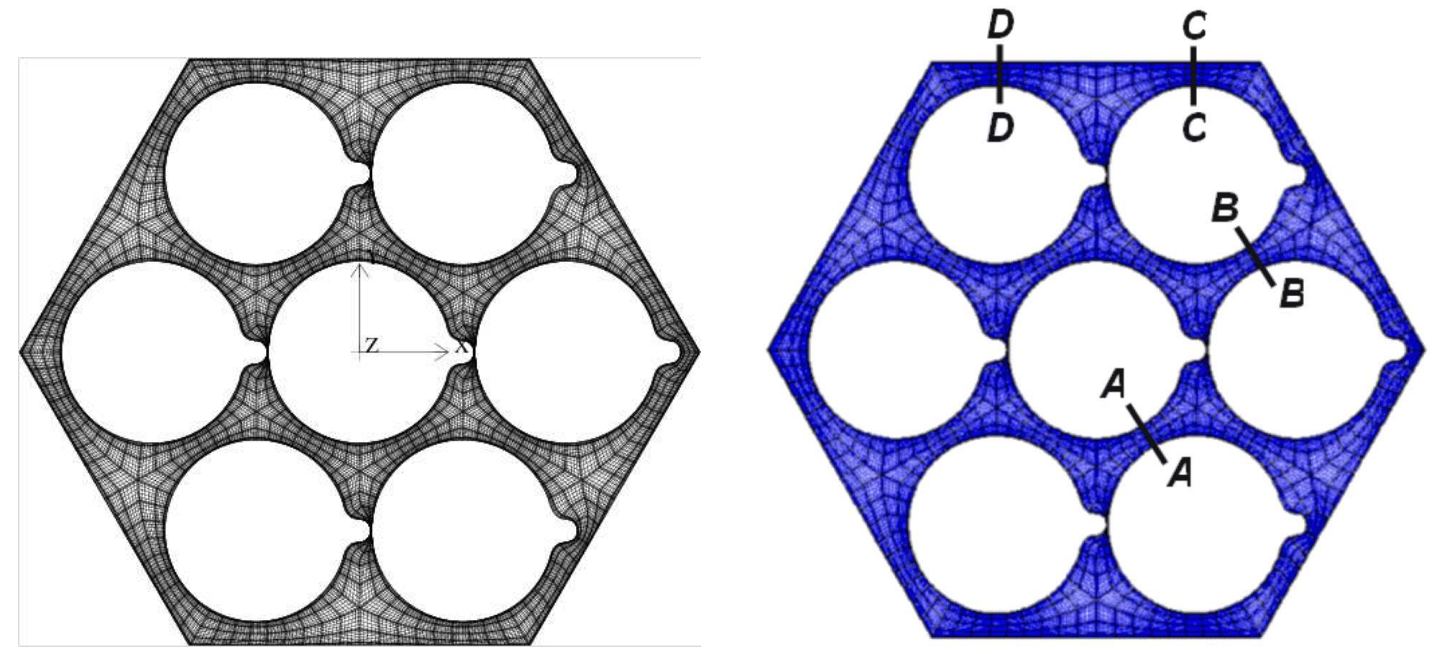

FIGURE 2 Cross-section of Spectral Element Mesh for the 7-pin Configuration. Subchannel interfaces are indicated on the right.

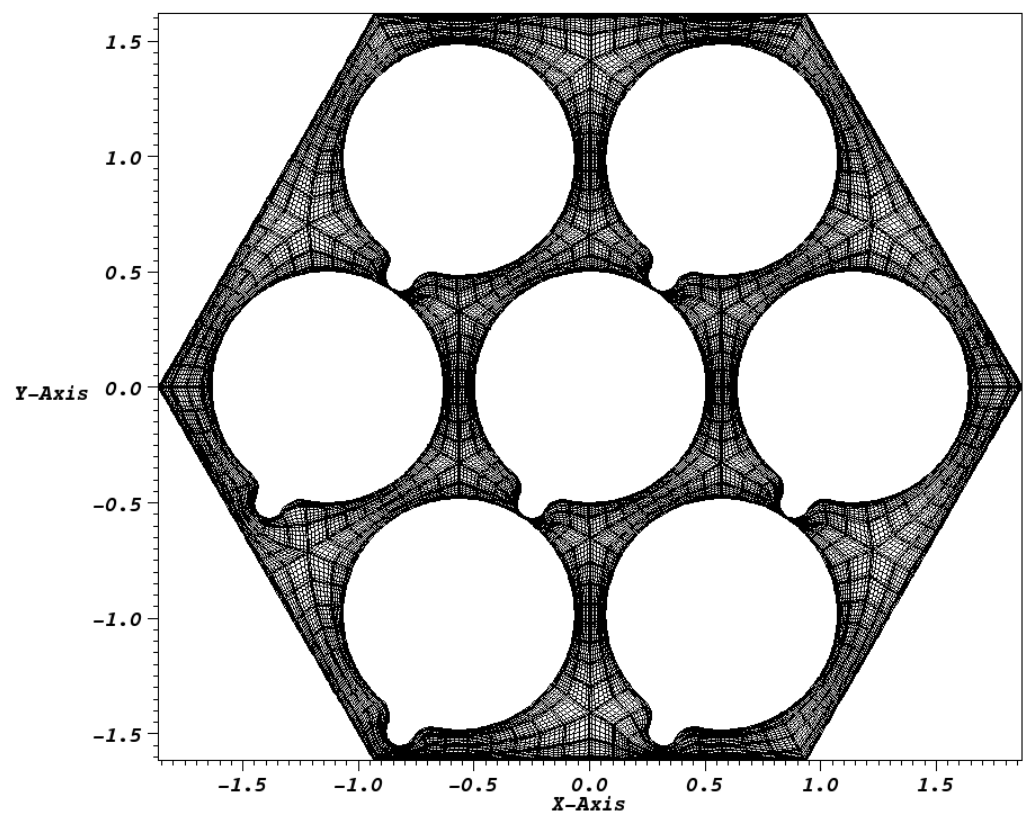

FIGURE 3 Cross-section of Spectral Element Mesh for 7-pin LES with $E=132,192, N=7$, and $z=9 D$. 


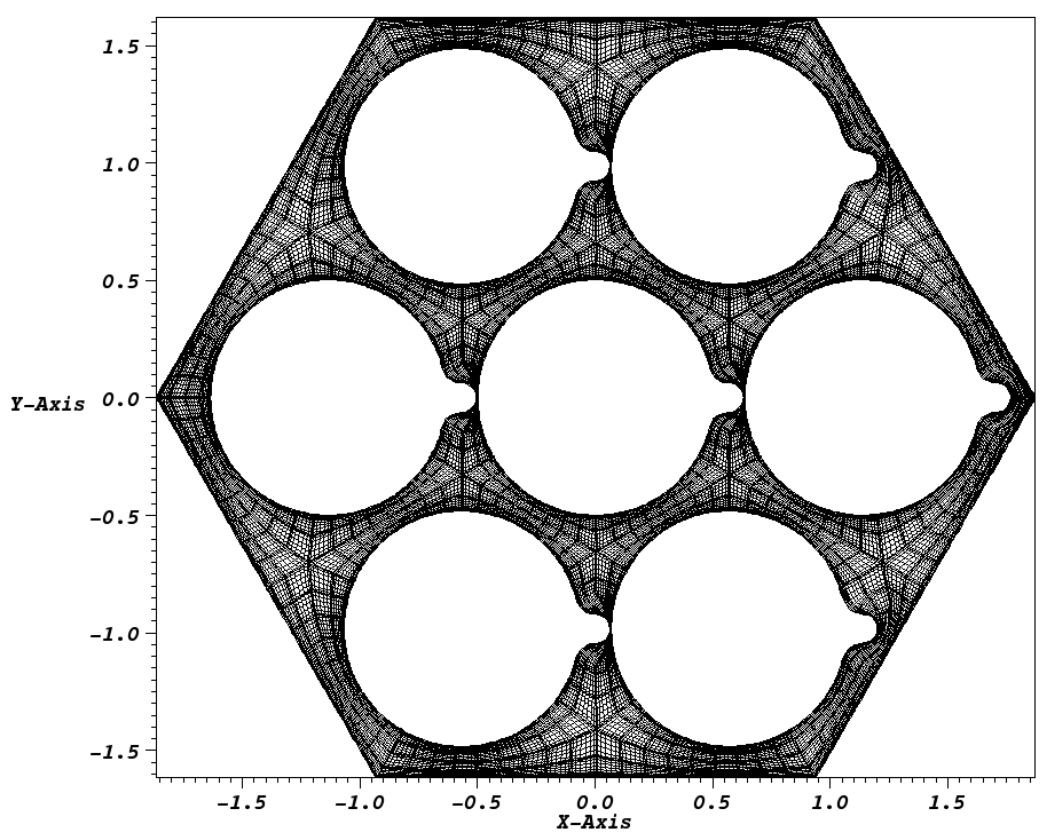

FIGURE 4 Cross-section of Spectral Element Mesh for 7-pin LES with $E=132,192, N=7$, and $z=0$.

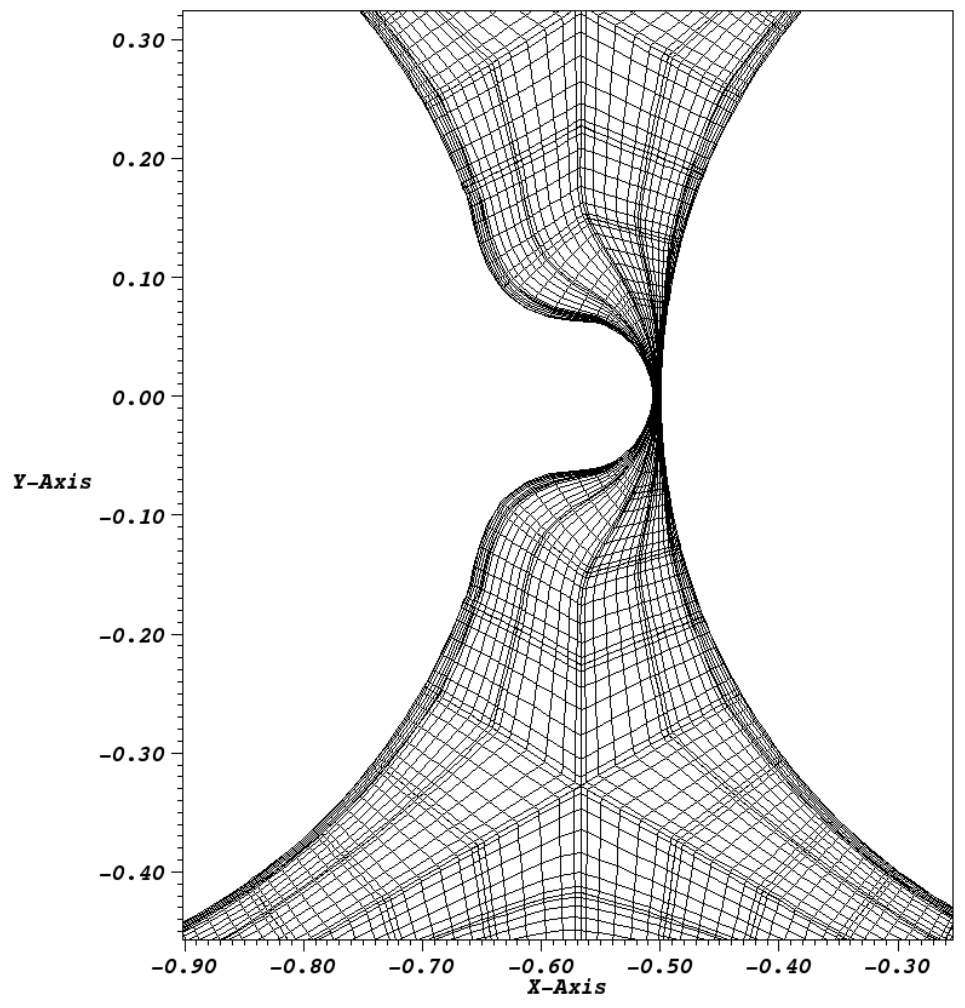

FIGURE 5 Detail of the Narrow Gap Region between a Wire and Adjacent Pin. 


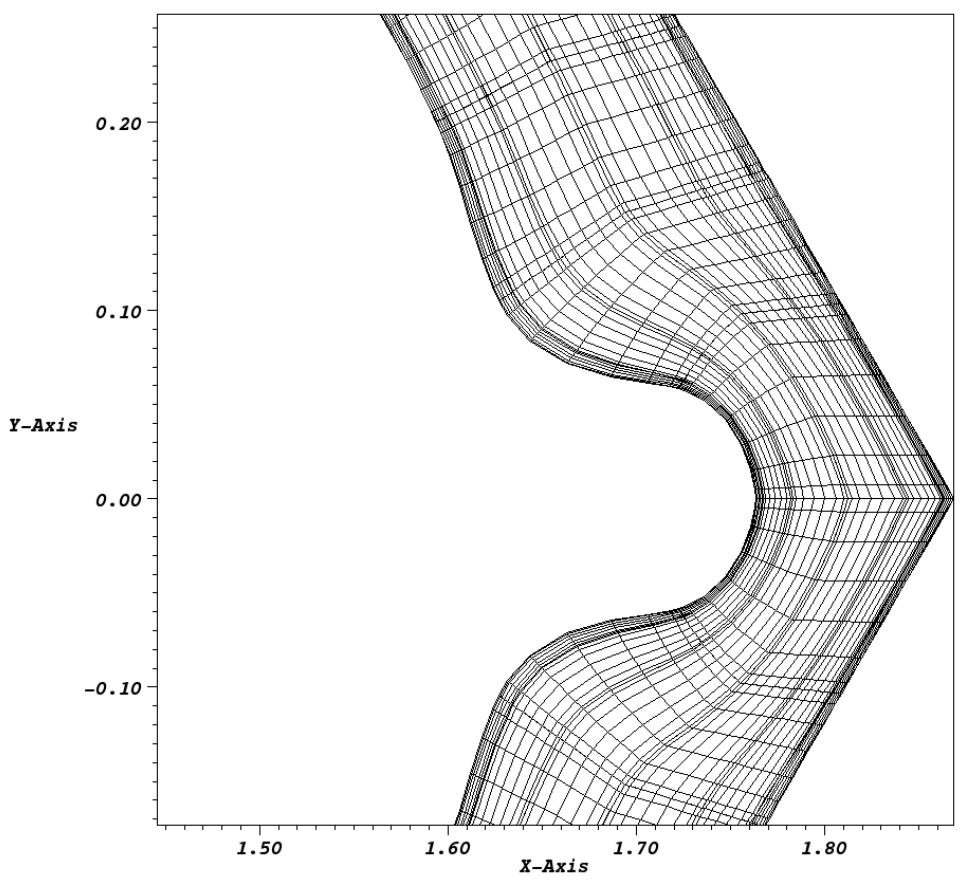

FIGURE 6 Detail of the Corner Region between a Wire and Can Corner. 


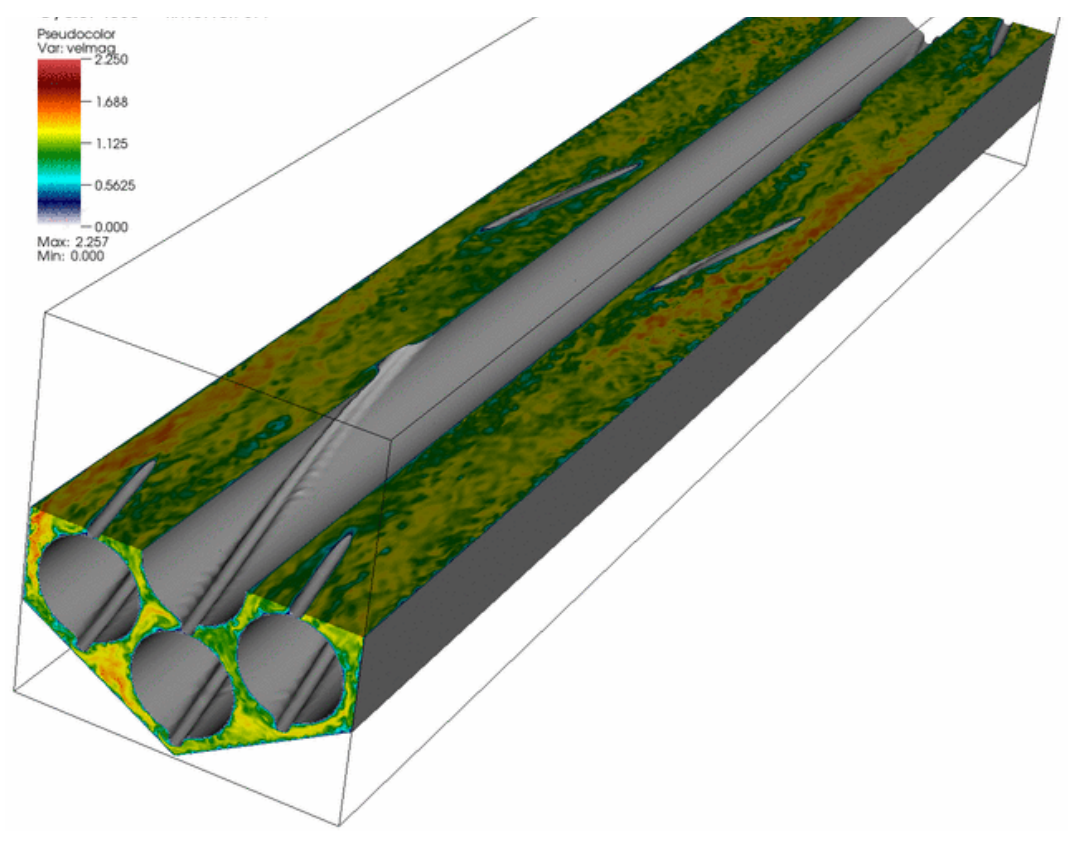

a)
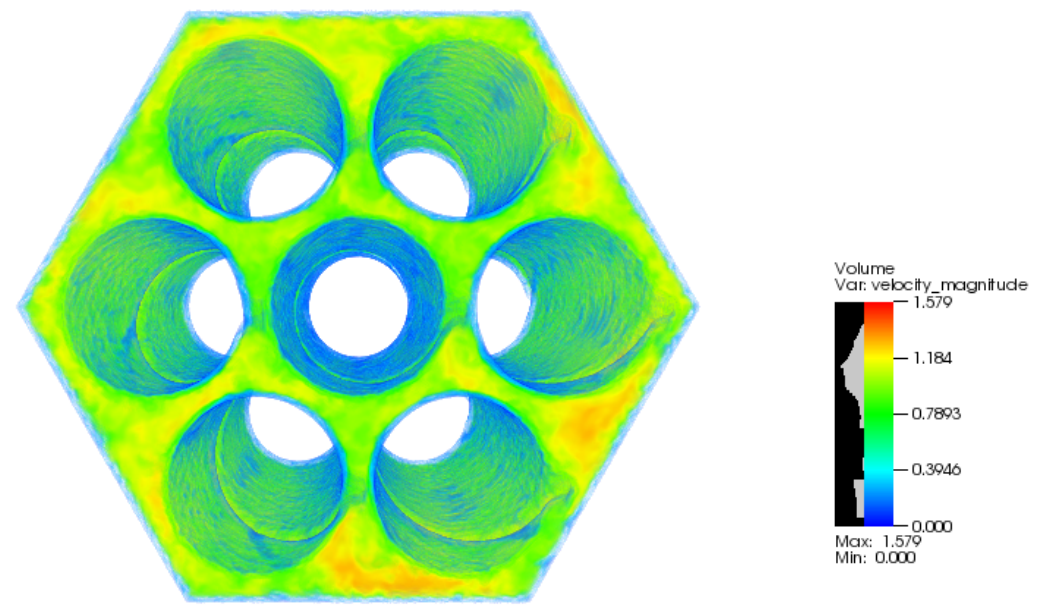

b) 

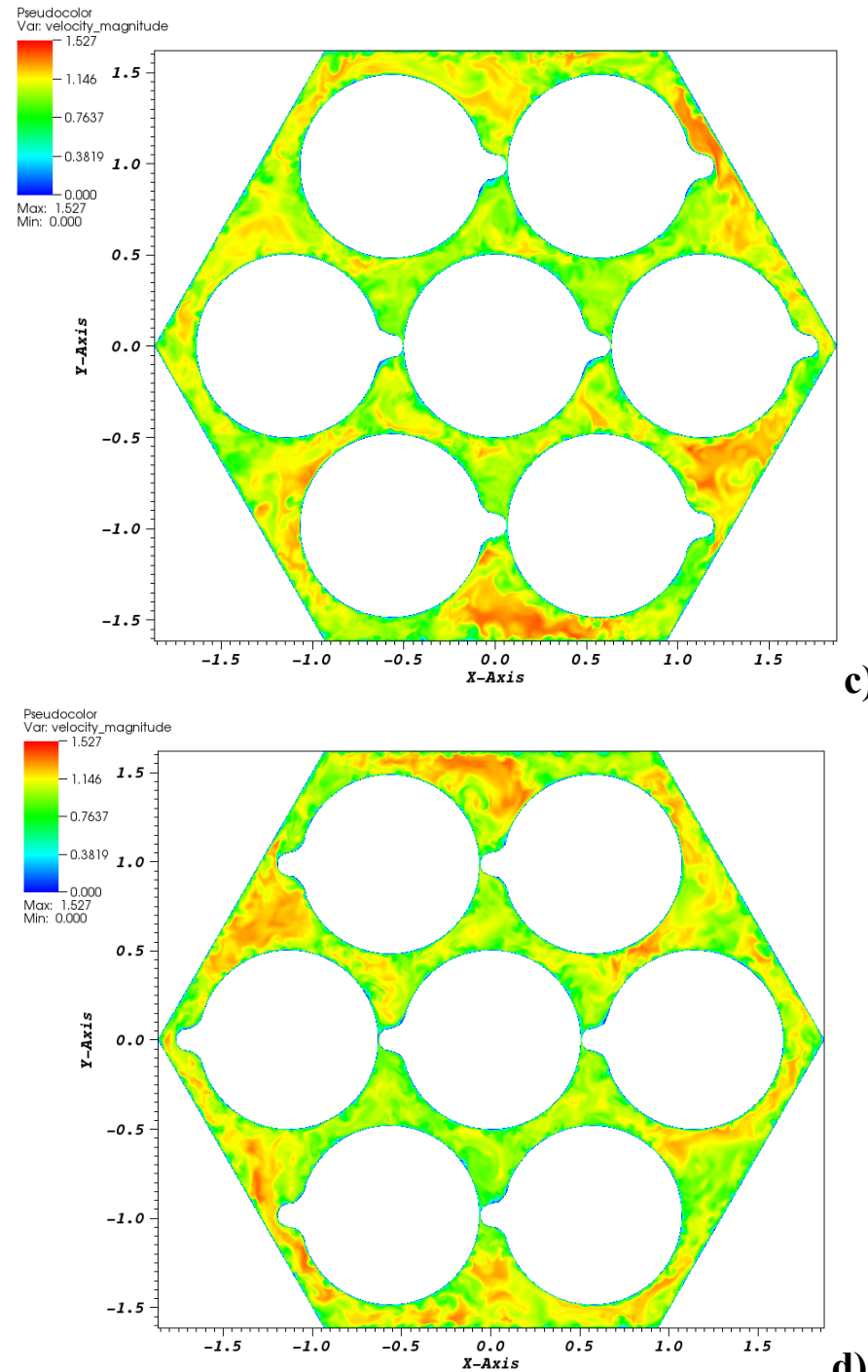

d)

FIGURE 7 Instantaneous Velocity Distributions for 7-pin LES Obtained with Nek5000. a) Cross section plot at the mid-section. b) Volume rendering plot. c-d) Cross sections in the streamwise direction. 


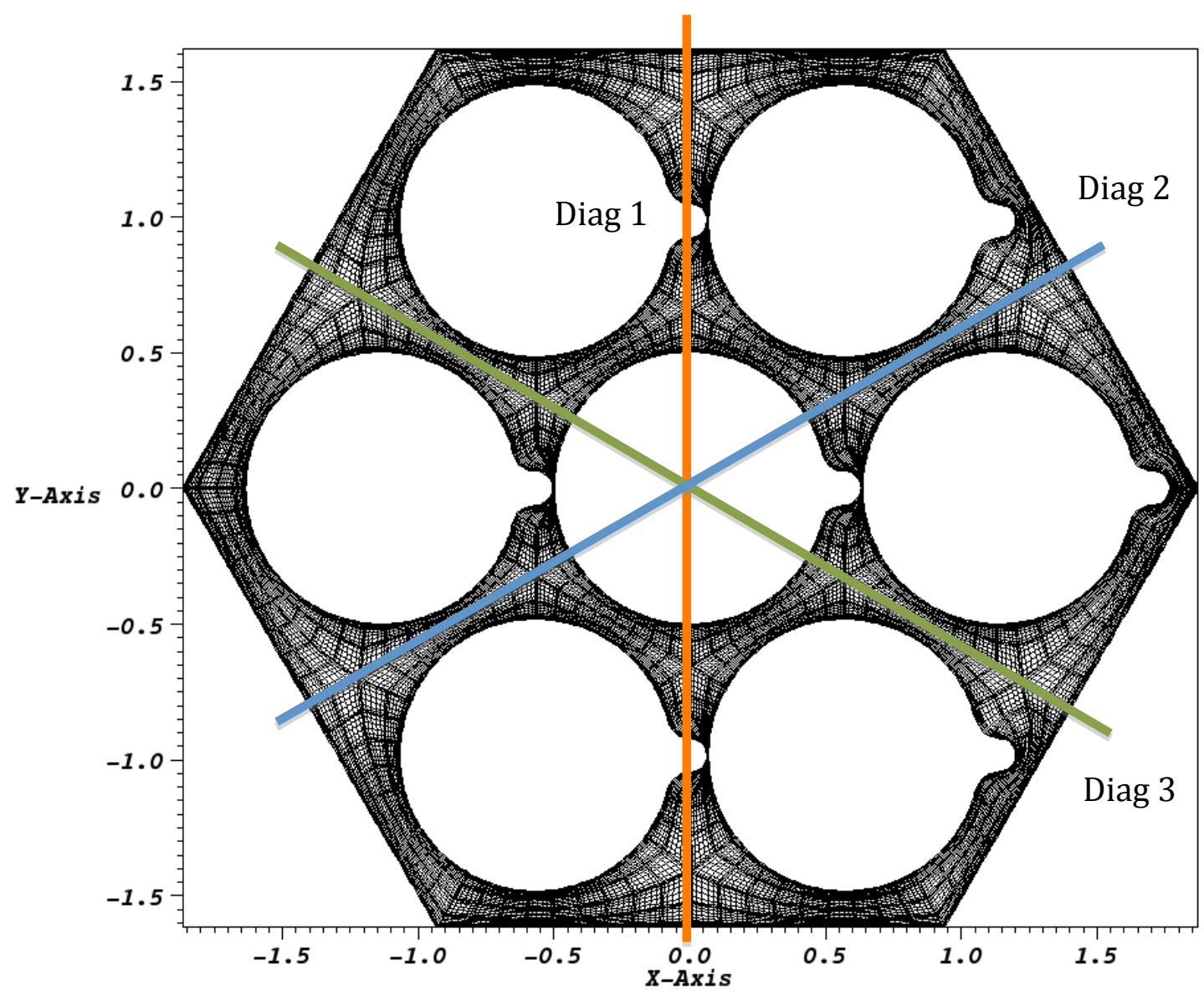

FIGURE 8 Diagonal Lines for Comparing Results. 
a)

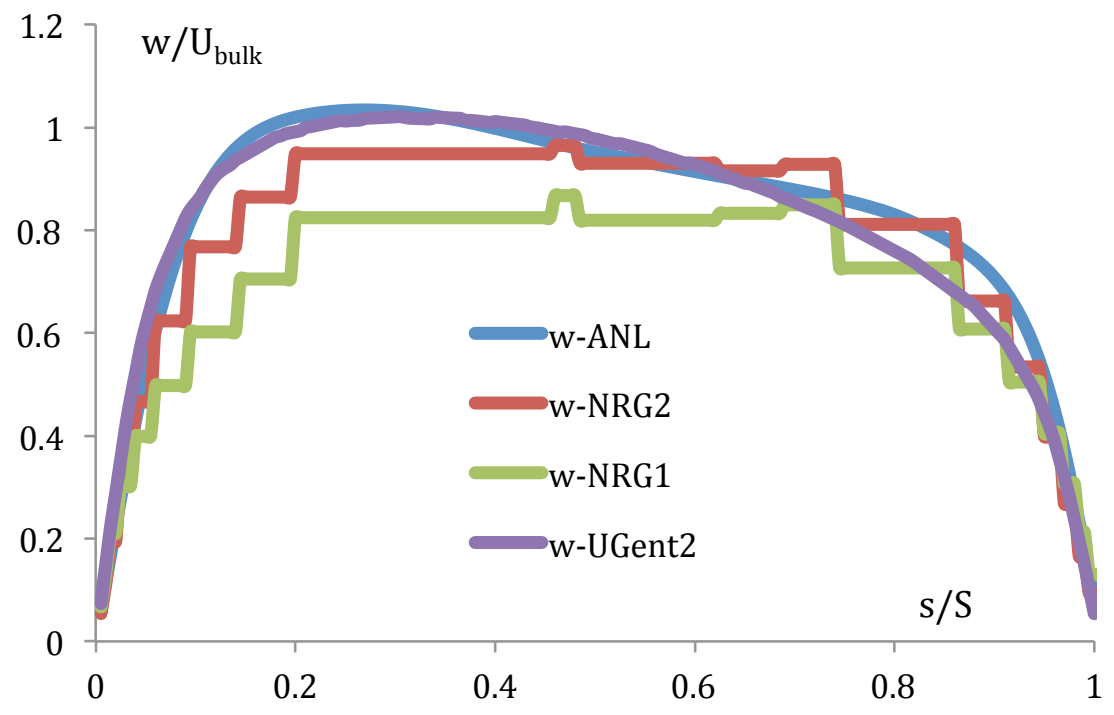

b)

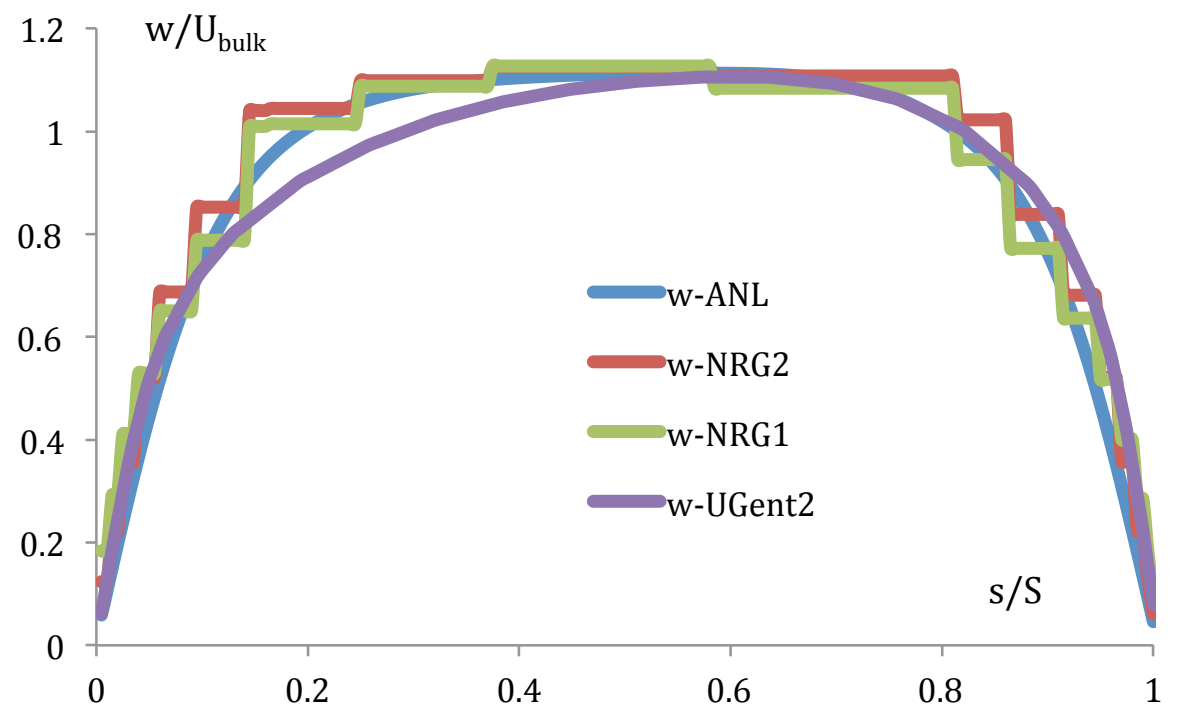


c)

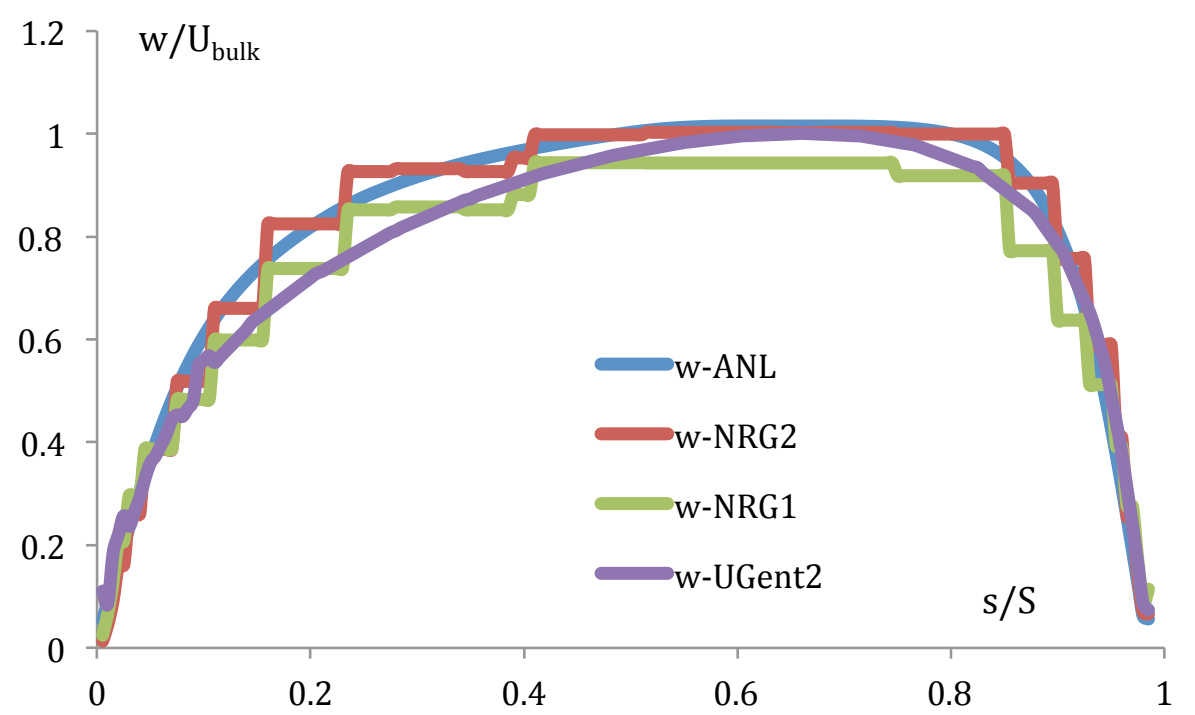

FIGURE 9. Streamwise velocity on plane $A-A$, Simulation 1. a) $\mathrm{z} / \mathrm{D}=10.64$, b) $\mathrm{z} / \mathrm{D}=15.72, \mathrm{c}) \mathrm{z} / \mathrm{D}=\mathbf{2 1 . 2 8}$.

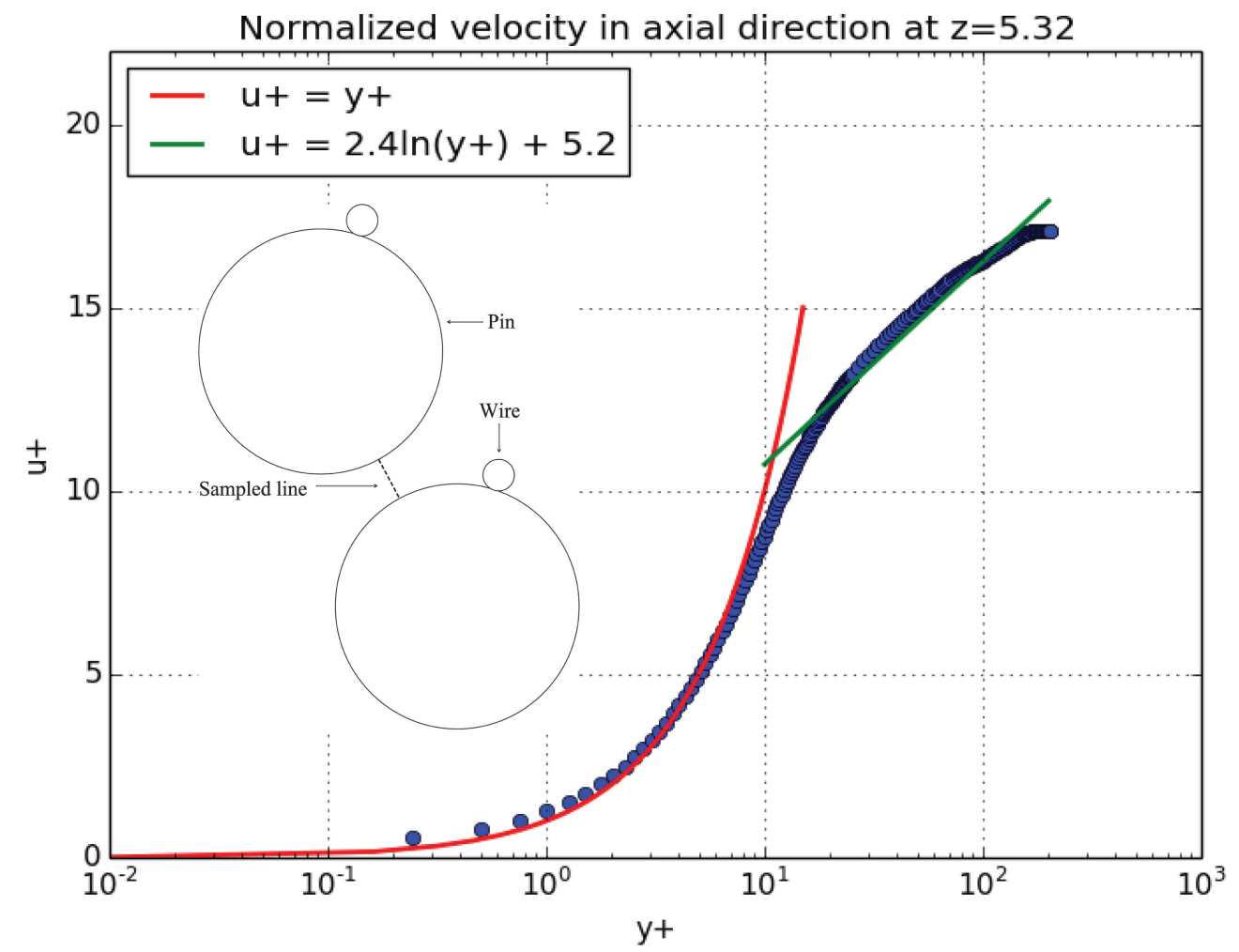

a) 


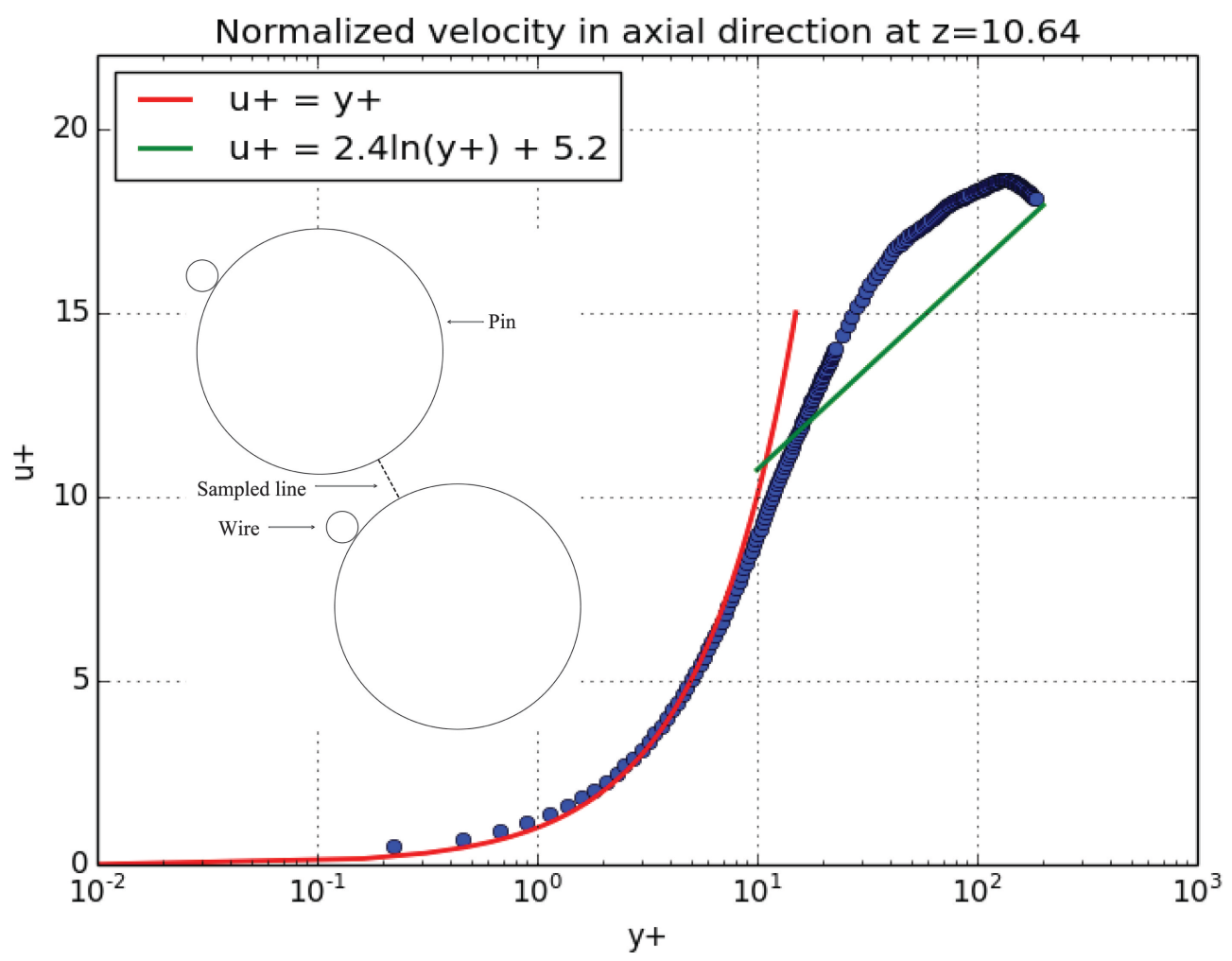

b)

FIGURE 10. Streamwise velocity in friction units on plane A-A. Simulation 1 at a) $\mathrm{z} / \mathrm{D}=\mathbf{5 . 3 2}$ and $\mathrm{b}) \mathrm{z} / \mathrm{D} 10.64$. 


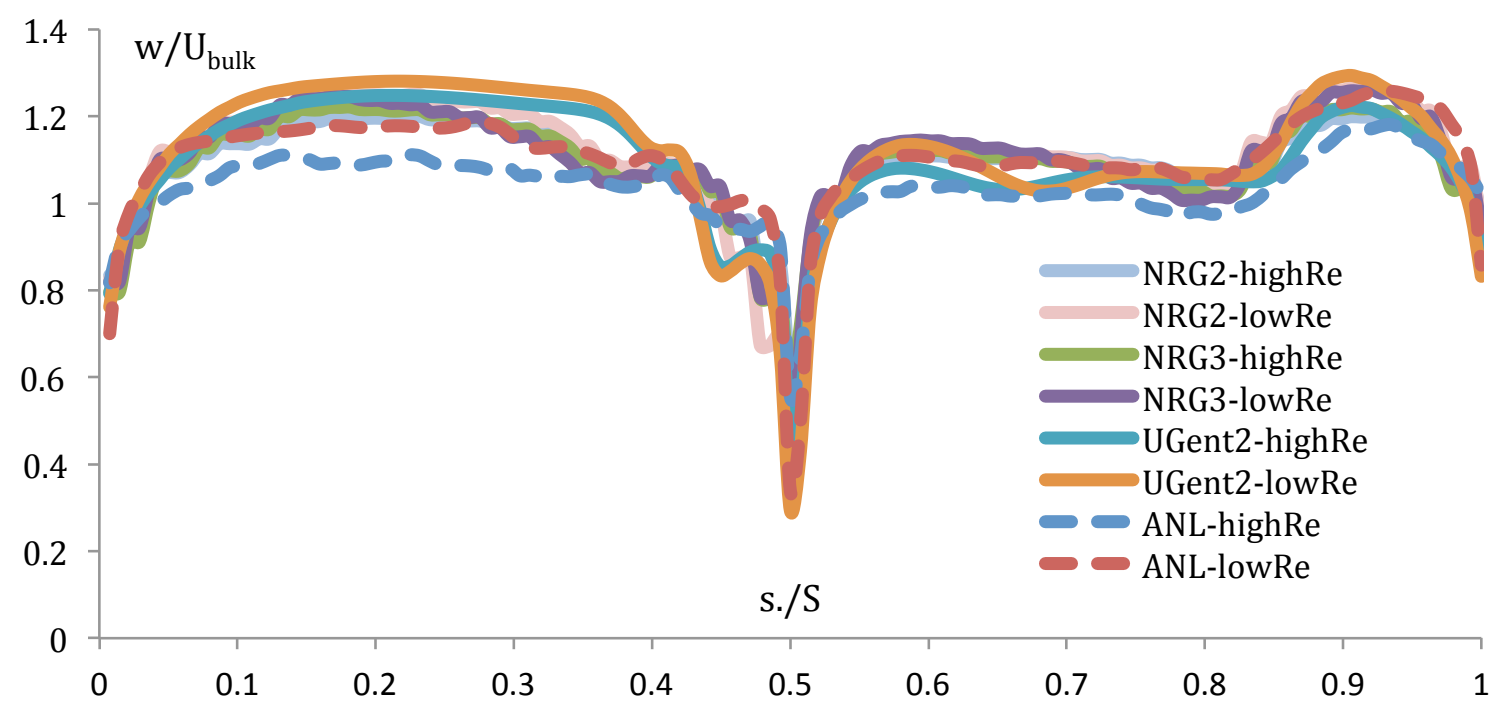

FIGURE 11. Streamwise velocity on Diagonal $1, \mathrm{z} / \mathrm{D}=5.32$. ANL, NRG-2 and UGent2 submissions.

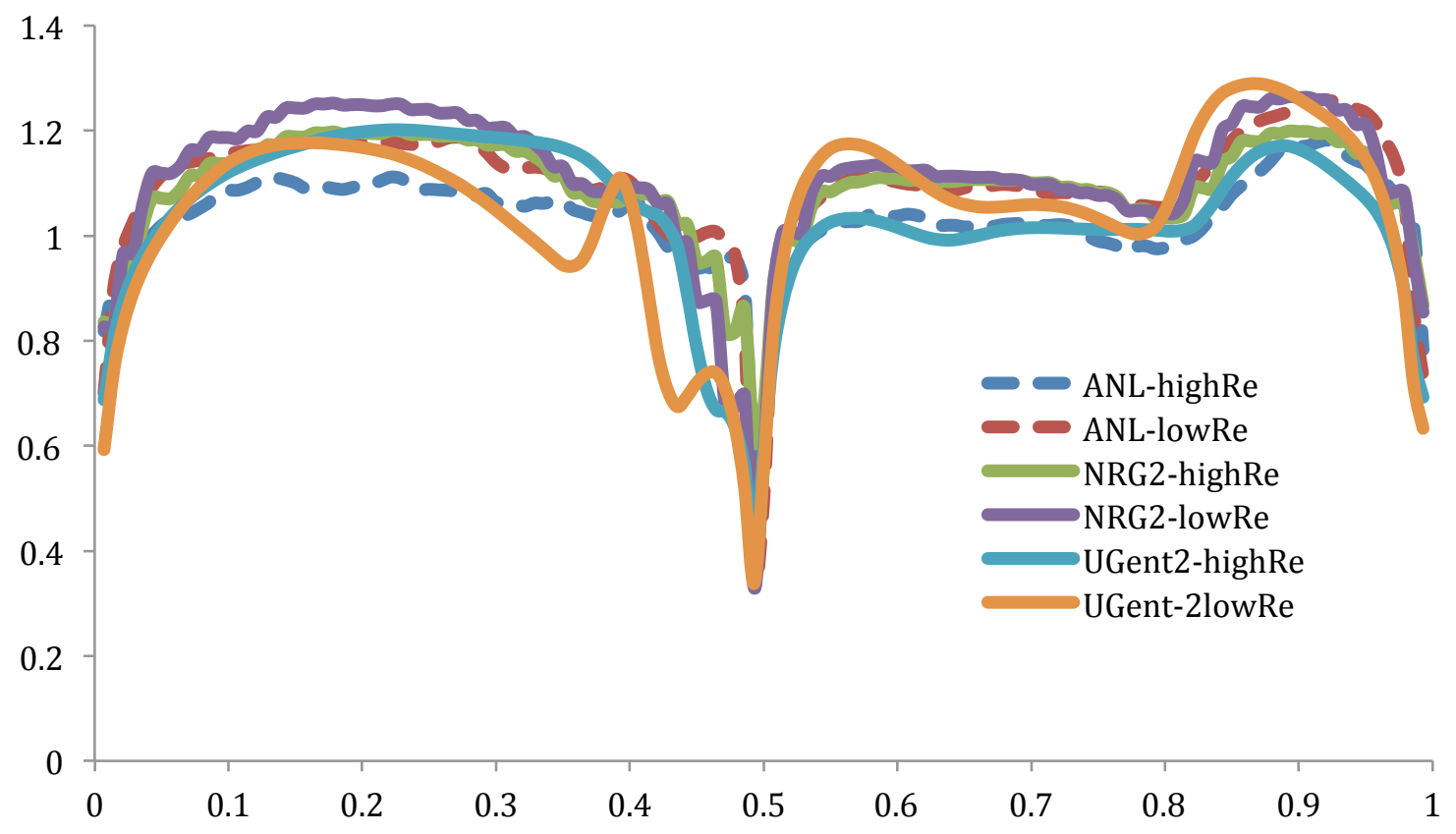

FIGURE 12. Cross velocity on Diagonal $1, \mathrm{z} / \mathrm{D}=5.32$. ANL, NRG-2 and UGent-2 submissions. 

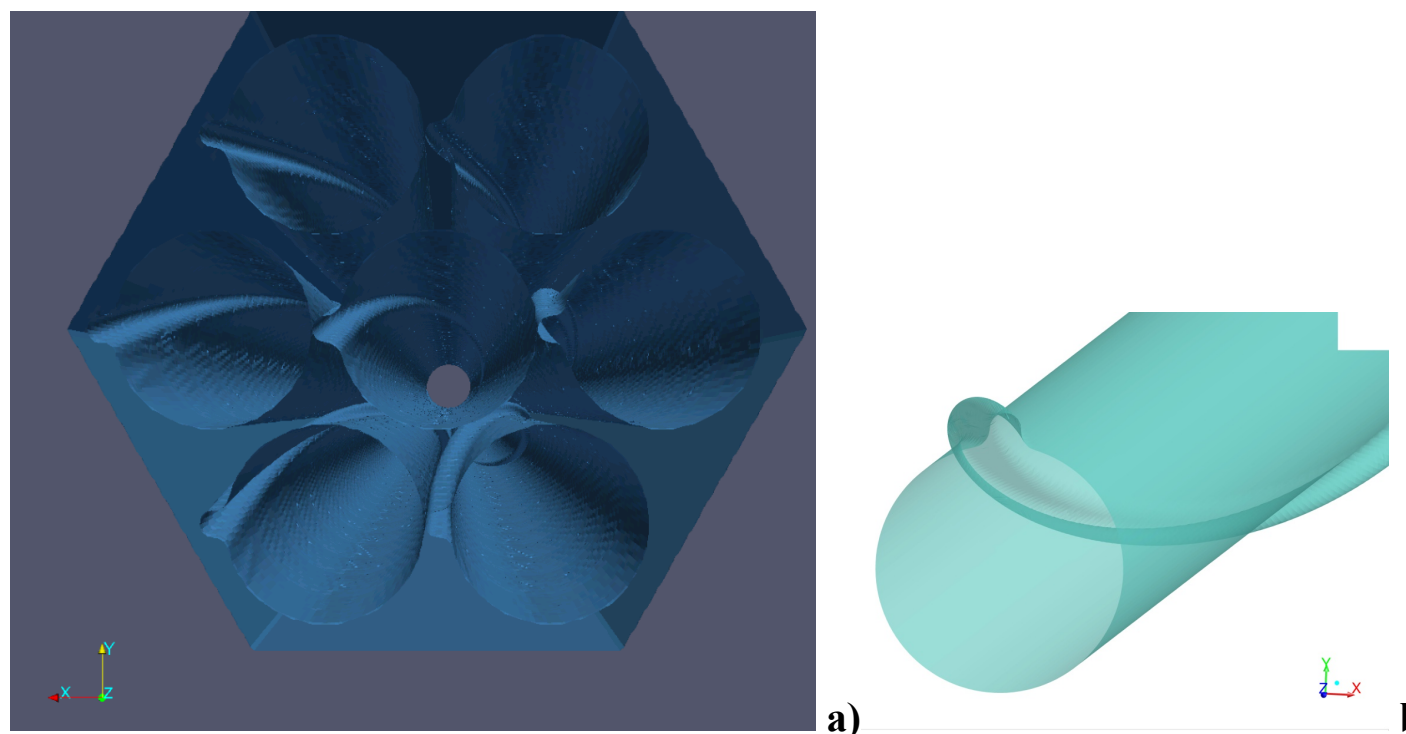

a)

b)

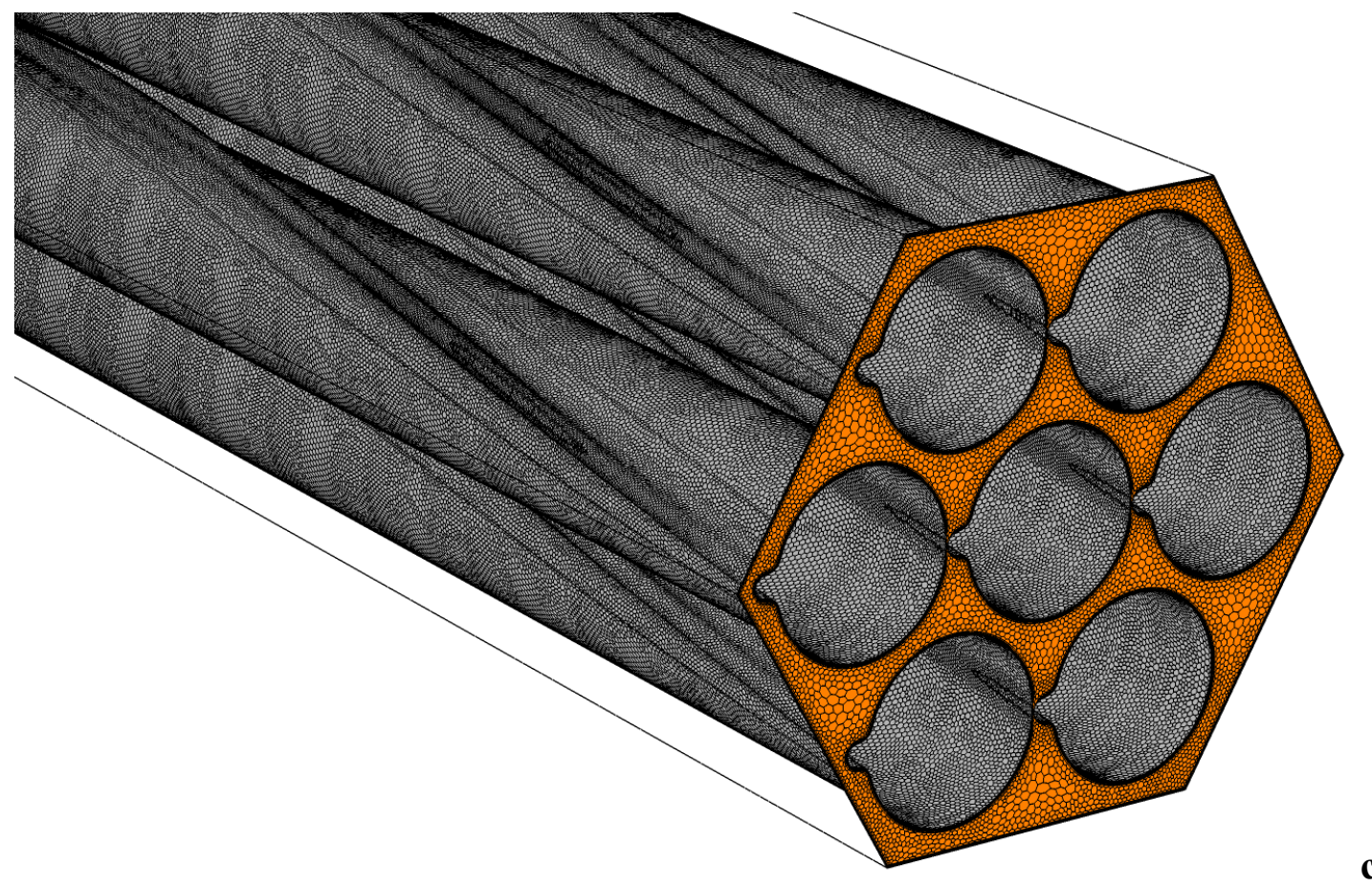

c)

FIGURE 13. a) Former surface representation (notice the taxellation) - UGent1. b) New surface representation-UGent2. c) Surface representative and mesh for the NRG calculations. 
a)

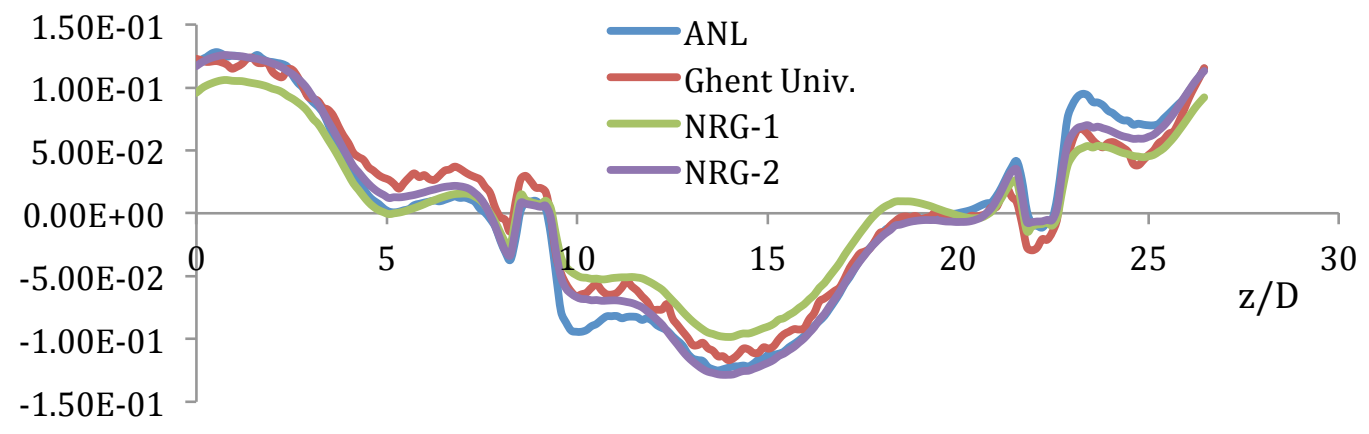

b)

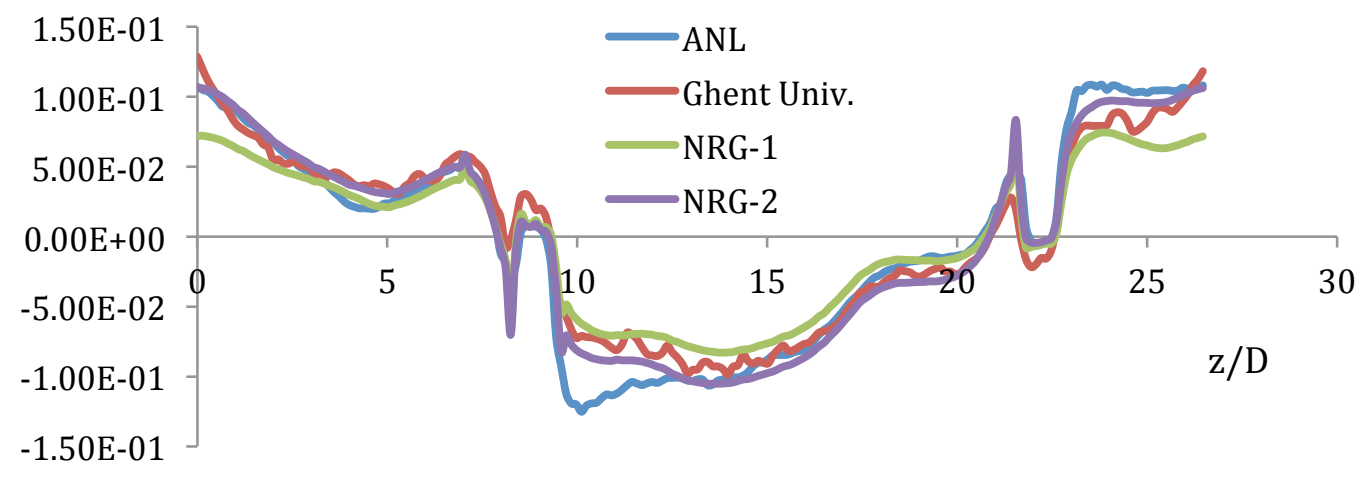

c)

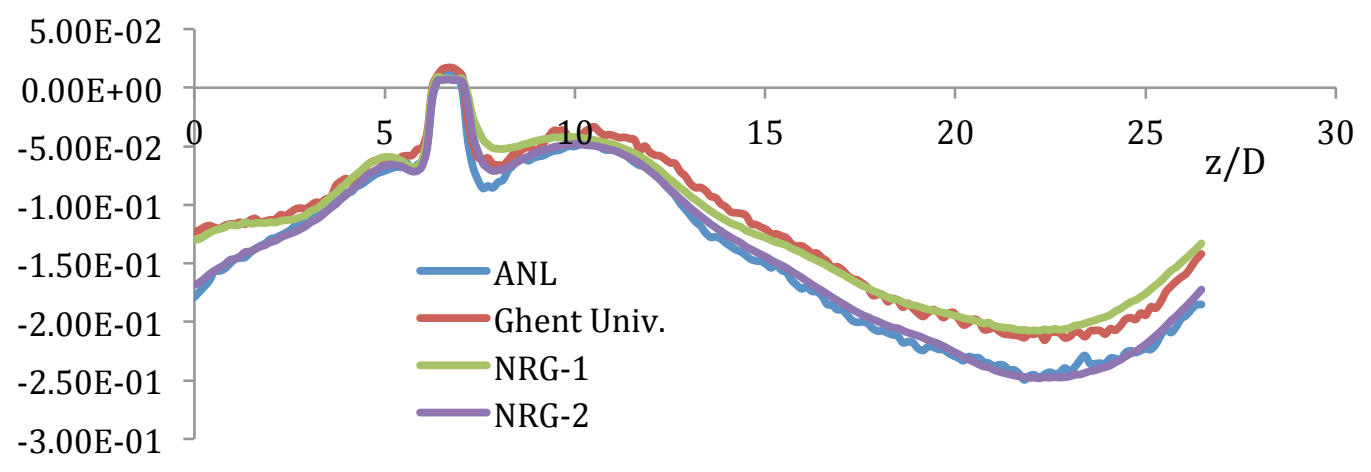

FIGURE 14. Plane, Cross Flows Normalized by $u_{b u l k}{ }^{*} g$ (where $g$ is the gap size without wire). Simulation 2. a) A-A, b) B-B, c) C-C. The calculation from Ghent University is UGent1. 
a)

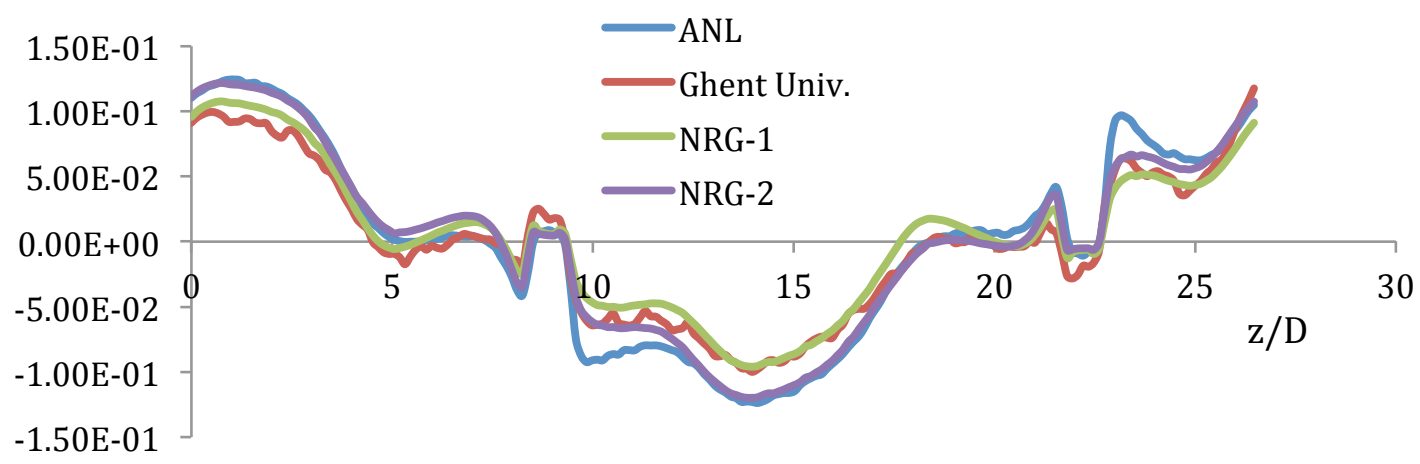

b)

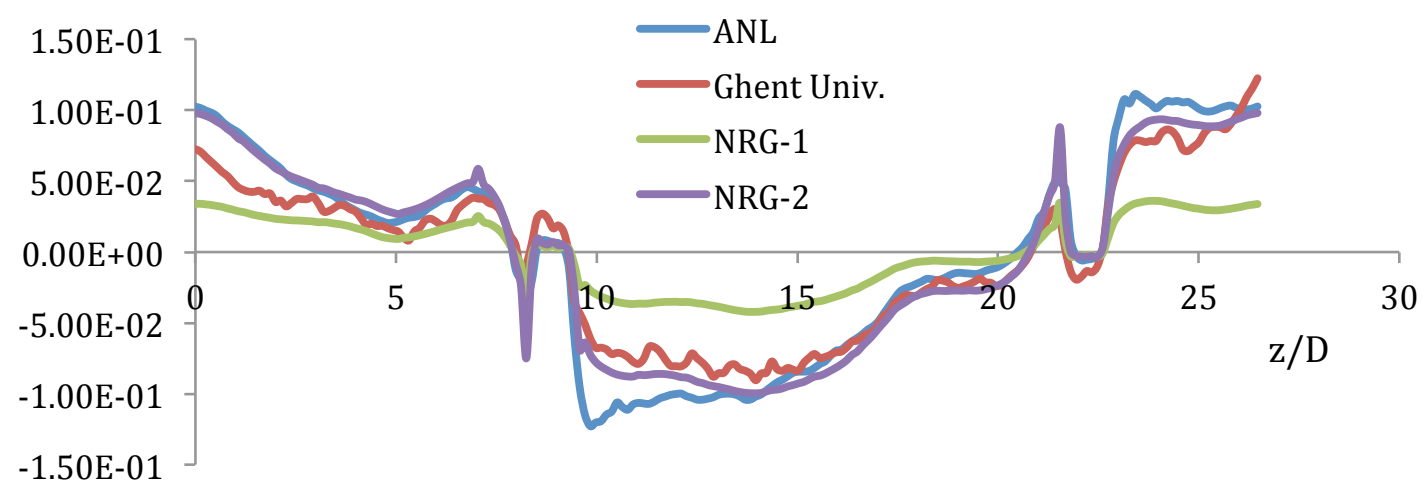

c)

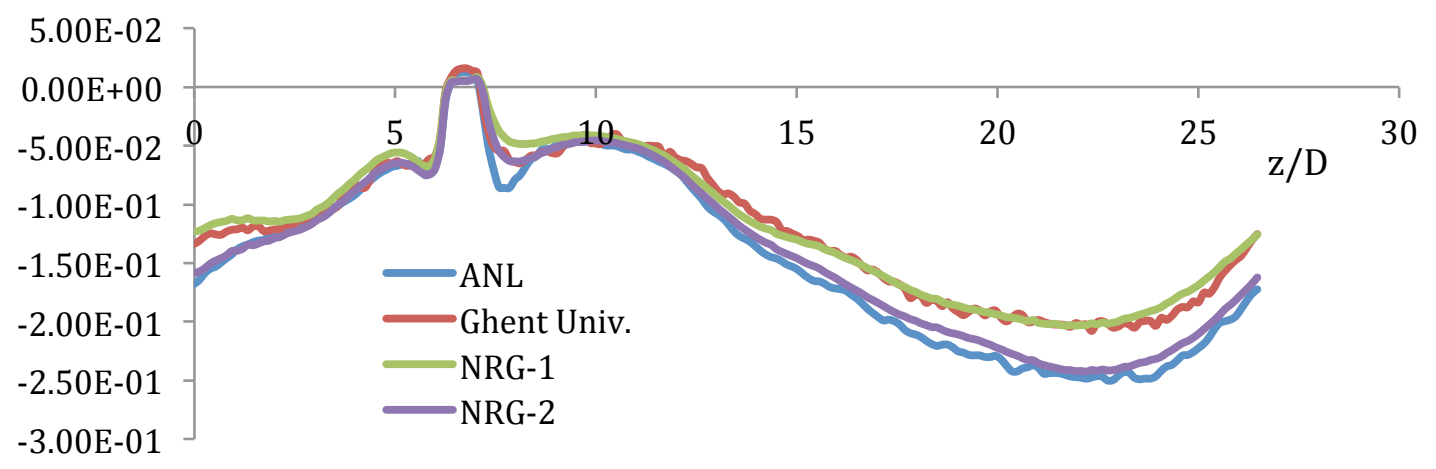

FIGURE 15. Plane, Cross Flows Normalized by $u_{b u l k}{ }^{*} g$ (where $g$ is the gap size without wire). Simulation 1. a) A-A, b) B-B, c) C-C. The calculation from Ghent University is UGent1. 


\section{TABLES}

TABLE 1. Data for Benchmark Simulation 1

\begin{tabular}{lllll}
\hline \multicolumn{1}{c}{ Parameter } & \multicolumn{1}{c}{ Value } & \multicolumn{1}{c}{ Parameter } & \multicolumn{1}{c}{ Value } \\
\hline $\mathrm{Re}_{\mathrm{D}}$ & 22,500 & Flat-to-flat $(\mathrm{F})$ & $3.2375 \mathrm{D}$ \\
$\mathrm{Re}$ & 9,457 & $\begin{array}{l}\text { Nominal clearance between } \\
\text { wire and adjacent pins }\end{array}$ & $0.00625 \mathrm{D}$ \\
& & Number of spans & 1 (periodic) \\
Pitch of rod bundle P & $1.13494 \mathrm{D}$ & & $0.42 \mathrm{D}$ \\
Pitch of wire H & $26.6 \mathrm{D}$ & $\mathrm{D}_{\mathrm{h}}$ & \\
\hline
\end{tabular}

TABLE 2. Data for Benchmark Simulation 2

\begin{tabular}{ll|ll}
\hline \multicolumn{1}{c|}{ Parameter } & \multicolumn{1}{c}{ Value } & \multicolumn{1}{c}{ Parameter } & \multicolumn{1}{c}{ Value } \\
\hline $\mathrm{Re}_{\mathrm{D}}$ & 50,000 & Flat-to-flat (F) & $3.2375 \mathrm{D}$ \\
$\mathrm{Re}$ & 21,000 & $\begin{array}{l}\text { Nominal clearance between } \\
\text { wire and adjacent pins }\end{array}$ & $0.00625 \mathrm{D}$ \\
Pitch of rod bundle P & $1.13494 \mathrm{D}$ & Number of spans & 1 (periodic) \\
Pitch of wire H & $26.6 \mathrm{D}$ & $\mathrm{D}_{\mathrm{h}}$ & $0.42 \mathrm{D}$ \\
\hline
\end{tabular}

TABLE 3 Velocity Comparisons 1 and 2 (as \% of bulk velocity)

\begin{tabular}{|c|c|c|c|c|c|}
\hline Simulation and Velocity & UGent-1 & UGent-2 & NRG-1 & NRG-2 & NRG-3 \\
\hline $\operatorname{Sim} 1-C 1(u)$ & 3.4 & 2.0 & 3.5 & 2.18 & 2.85 \\
\hline Sim $1-C 1(v)$ & 1.86 & 1.4 & 1.84 & 1.6 & 1.81 \\
\hline $\operatorname{Sim} 1-\mathrm{C} 1(\mathrm{w})$ & 10.8 & 7.7 & 9.25 & 6.59 & 8.79 \\
\hline $\operatorname{Sim} 1-\mathrm{C} 2(\mathrm{u})$ & 2.78 & 2.1 & 3.65 & 2.94 & 3.51 \\
\hline $\operatorname{Sim} 1-C 2(v)$ & 2.51 & 1.9 & 3.28 & 2.46 & 3.06 \\
\hline Sim1 - C2 (w) & 9.37 & 6.9 & 11.38 & 6.38 & 6.89 \\
\hline $\operatorname{Sim} 2-C 1(u)$ & 2.83 & 2.5 & 3.05 & 1.68 & 1.92 \\
\hline $\operatorname{Sim} 2-C 1(v)$ & 1.31 & 2.6 & 1.28 & 1.08 & 1.20 \\
\hline $\operatorname{Sim} 2-\mathrm{C} 1(\mathrm{w})$ & 9.77 & 11.0 & 9.41 & 6.81 & 6.56 \\
\hline $\operatorname{Sim} 2-C 2(u)$ & 2.07 & 2.2 & 2.74 & 2.14 & 2.31 \\
\hline $\operatorname{Sim} 2-C 2(v)$ & 1.93 & 2.0 & 2.70 & 1.98 & 2.21 \\
\hline $\operatorname{Sim} 2-\mathrm{C} 2(\mathrm{w})$ & 7.65 & 6.8 & 12.6 & 7.09 & 7.88 \\
\hline
\end{tabular}


TABLE 4 Comparison 3 for Cross-flow 2 (as \% of bulk velocity)

\begin{tabular}{lccccc}
\hline & \multicolumn{7}{c}{ UGent- } \\
Simulation and Plane & UGent-1 & 2 & NRG-1 & NRG-2 & NRG-3 \\
\hline & & & & & \\
Sim1 - C3 (A) & 2.03 & 1.02 & 2.19 & 1.04 & 1.38 \\
Sim1 - C3 (B) & 2.01 & 0.97 & 4.66 & 1.32 & 1.61 \\
Sim1 - C3 (C) & 2.86 & 1.15 & 3.12 & 0.88 & 1.73 \\
Sim2 - C3 (A) & 1.71 & 1.08 & 2.20 & 0.92 & 1.09 \\
Sim2 - C3 (B) & 1.82 & 1.09 & 2.40 & 1.27 & 1.4 \\
Sim2 - C3 (C) & 2.64 & 1.06 & 2.79 & 0.67 & 0.96 \\
\hline
\end{tabular}

